\title{
“CIENCIA Y TECNOLOGÍA EN ARGENTINA: TRANSFORMACIÓN DEL ROL DE LAS INSTITUCIONES CIENTÍFICAS EN UN MUNDO MERCANTIL. EL CASO DE LA UNIVERSIDAD PÚBLICA ARGENTINA" "
}

\author{
Ariel Langer ${ }^{2}$ \\ Facultad Latinoamericana en Ciencias Sociales (FLACSO)
}

\begin{abstract}
RESUMEN
El presente artículo está basado en la tesis homónima presentada en la Maestría de Ciencia Política y Sociología de la Facultad Latinoamericana en Ciencias Sociales (FLACSO), la cual se elaboró a partir de las bases teóricas y empíricas construidas en el marco de un Proyecto de investigación en redes con sede en el Programa de Educación, Economía y Trabajo (PEET) del Instituto de Investigaciones en Ciencias de la Educación de la Facultad de Filosofía y Letras de la UBA. Su objetivo general es comprender la transformación de las políticas y las instituciones científicas argentinas a partir del análisis de su rol social en cada momento histórico. Para ello se estudian los factores que intervienen en el desarrollo de la ciencia en relación con la producción de mercancías. Tomamos como punto de partida la hipótesis de que, en nuestra sociedad, el proceso económico global va influyendo sobre la concepción social respecto a qué es hacer ciencia y qué rol deben tener sus instituciones. De esta forma, se observa cómo se fueron transformando las políticas y las instituciones de ciencia en Argentina a la par de los cambios en la estructura económica del país. Si bien la temática es abordada en forma general, a fin de describir concretamente estos procesos, se toma como caso de estudio a la Universidad Pública argentina. El período bajo estudio es centralmente el de los últimos 25 años de su historia, realizándose además un análisis empírico detallado de su situación actual.
\end{abstract}

\begin{abstract}
:
This paper is based on the master thesis presented in the Master of Politic and Social Science in Facultad Latinoamericana de Ciencias Sociales (FLACSO), which was made starting from the theoretical and empirical bases of a research performed by Programa de Educación, Economía y Trabajo (PEET) del Instituto de Investigaciones en Ciencias de la Educación de la Facultad de Filosofía y Letras de la UBA. Through an analysis of the politics of the scientific institutions in Argentina as well as their social role, this paper's objective is to comprehend the transformations these institutions have undergone throughout different points in this country's history. To this end, it is necessary to study the factors that intervened in the scientific development within Argentina as well as its relationship to the commodities production. The basic hypothesis proposed by this paper is that, within Argentine society, the general economic process has influenced the construction of the social conception of what it means to practice science as well as the role that scientific institutions play in the country. Consequently, this paper will analyze how Argentine scientific institutions and their politics have transformed in a manner parallel to the changes in the economic structure of the country. Although this topic will be studied in general terms, this paper will use the Argentine Public University as a case study so as to describe these processes in a concrete manner. The time frame studied in this paper is that of the last 25 years of Argentine history but also includes a detailed, empirical analysis of the current situation of the country.
\end{abstract}

\section{Introducción}

El presente artículo está basado en la tesis presentada en la Maestría de Ciencia Política y Sociología de la Facultad Latinoamericana en Ciencias Sociales (FLACSO). La misma, a su vez, se elaboró a partir de las bases teóricas y empíricas construidas en el marco del Proyecto PICTR00013 $3^{3}$ con sede en el Programa de Educación, Economía y Trabajo (PEET) del Instituto de Investigaciones en Ciencias de la Educación de la Facultad de Filosofía y Letras de la UBA. 
El objetivo general de la tesis es comprender la transformación de las políticas y las funciones de las instituciones científicas-universitarias argentinas a partir del análisis de la evolución histórica del concepto denominado "idea de universidad". A fin de cumplir con ello, se construye un marco teórico indagando diversidad de enfoques sobre las nociones de ciencia, universidad y sus funciones, así como entre los estudios sociales de la ciencia (o CTS). La particularidad y originalidad de esta construcción es que las ideas comentadas se presentan en un marco dinámico (histórico) donde la transformación de las nociones se refiere a las necesidades creadas por la estructura económico-social en cada país y, por tanto, al espacio en la división internacional del trabajo que cada uno de ellos ocupa. Se adopta un enfoque donde las problemáticas de la ciencia (y por extensión de la universidad como institución científica) se conciben como parte integrante del sistema productivo de una nación.

En el caso particular de este trabajo se tiene como objetivo general comprender la transformación de las políticas y las instituciones científicas argentinas a partir del análisis de su rol social en cada momento histórico. Esto implicará estudiar los factores que intervienen en el desarrollo de la ciencia en relación con la producción de mercancías. Tomaremos como base del trabajo la hipótesis de que, en nuestra sociedad, el proceso económico global va influyendo sobre la concepción social respecto a qué es hacer ciencia y qué rol deben tener sus instituciones. De esta forma, se observará cómo se fueron transformando las políticas y las instituciones de ciencia en Argentina a la par de los cambios en la estructura económica del país.

\section{Parte 1 \\ Persistencia y transformación de rasgos y funciones históricas de la universidad argentina: Presentación del problema}

\section{1. Método de abordaje}

El método adoptado para estudiar la transformación de las instituciones productoras de conocimiento tiene su eje en la evolución histórica del concepto denominado por los filósofos alemanes de la Ilustración como "idea de universidad". Su primer paso radica en observar cómo se presenta la discusión sobre qué es la ciencia y cuál es su pertinencia. Luego reflexionamos sobre sus condicionantes histórico-estructurales al enmarcar la actividad científica como parte del sistema productivo. En una tercera y final etapa volvemos a observar las prácticas y nociones de los científicos universitarios, pero a través del cristal teórico adquirido en los dos momentos anteriores.

Un resultado del proyecto PICTR00013 es el reconocimiento de la fragmentación entre los grupos universitarios a partir de la coexistencia de diversas orientaciones político-académicas que, en ciertas ocasiones, no son reconocidas por sus integrantes. Así es que "se reproducen lógicas enfrentadas y se determina su continuidad por vía de la competencia entre recursos, ya no tan escasos como en períodos previos" (Riquelme, 2008b; p.474). Sumándose a esta lógica muchas veces caótica del sistema científico argentino y especialmente de su universidad, se encuentran las distintas concepciones y enfoques teóricos que discuten lo que lo que las instituciones científicas son o deberían ser. Finalmente, al conjunto de contraposiciones se suman los debates que ocurren en el nivel de las políticas científicas y universitarias. Por tanto, consideramos necesario ordenar la multiplicidad de prácticas y discursos que generalmente se presentan transpuestos a fin de comprender cuáles son las posturas que se enfrentan y dónde pueden hallarse sus raíces. A tal fin, y centrándonos en la historia de la universidad, se indaga sobre el momento en que surge cada lógica, así como su persistencia y transformación dentro de las instituciones científicas a través del tiempo.

De esta forma, identificamos, en primera medida, los principales rasgos de dos modelos de universidad - el usualmente conocido como humboldtiano (proveniente de la filosofía ilustrada alemana y del que tomamos el concepto inicial de "idea de universidad") y el que aquí llamamos tradicional argentino ${ }^{4}$ (proveniente de la universidad argentina del período 55-66)- para luego analizar 
las transformaciones resultantes de lo que denominamos primera y segunda generación de reformas de mercado (80-90 y post-2001).

Entre los filósofos alemanes el concepto de "idea de universidad" implicaba una institución constituida como espacio (comunidad) dedicada al desarrollo de la razón, la cual debía estar gobernada únicamente a través de leyes fundamentadas en la reflexión filosófica y, por tanto, con un claro espíritu universal. Su objetivo y principal aporte a la sociedad era la trascendencia de los límites históricos a través del progreso de la conciencia social generada por la actividad científica. El modelo humboldtiano que aquí asumimos es aquel que entiende a la universidad como la institución donde la razón se auto-determina por sus propias leyes y se encuentra destinada a trascender su sociedad.

La lógica de producción de conocimiento derivada de estos principios resulta de importancia en la tesis en tanto, si bien no necesariamente en forma absoluta, se halla repetidamente como elemento constitutivo de las instituciones científicas del país, formando parte de las ideas de los investigadoresdocentes y en la retórica de otros actores del sistema. De hecho, una porción importante de las críticas a la universidad actual y de su proceso de transformación se desarrollan en relación a las características de este modelo: el ataque al "aislamiento" o torre de marfil, la necesidad de potenciar los niveles de especialización, fragmentar el saber, hacer depender a la ciencia básica de potenciales aplicaciones y la construcción por parte de los grupos universitarios e incluso por estudiosos y políticos de una nueva noción de autonomía de la ciencia.

Otra de las lógicas presentes en la universidad actual es la basada en los principios elaborados en la Reforma del 18: las ideas sobre des-elitización, autonomía y democratización (co-gobierno) en gran medida provienen de este momento. Sin embargo, presentamos estos principios en relación con el

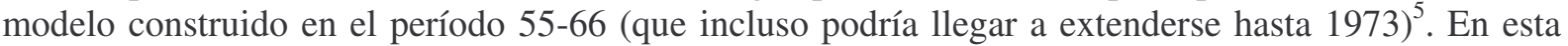
etapa, los rasgos reformistas aparecen en conjunto con principios planificadores y del fomento de las ciencias básicas dentro de la institución, características del modelo lineal de innovación surgido a nivel global hacia la mitad del siglo XX.

Pasado el proceso militar de los setenta, se inicia otro período que dejará importantes huellas en las concepciones de los individuos sobre la universidad y en las formas que esta adquiere. Durante las décadas del ochenta y noventa se incorporan mecanismos individuales y/o de mercado que afianzan nuevos atributos y funciones que hoy aparecen naturalizados pero que implicaron un fuerte giro en la historia de la institución. Por ejemplo, el surgimiento de la figura del investigador-gerente, la instauración de lógicas privadas para el manejo de fondos públicos, nuevas formas de seleccionar temas de investigación y el surgimiento de la categoría vinculación como nueva función de la universidad.

Luego de la crisis de 2001 el eje de transformación sigue siendo la producción de conocimiento, sin embargo, los aspectos centrales que han sufrido cambios difieren en relación a las dos décadas pasadas. Las mutaciones discursivas y en el nivel de las políticas han hecho que gran parte de los cambios provengan de las nuevas estrategias diseñadas para el sector y del mayor interés puesto en la atención a las demandas sociales (con las múltiples interpretaciones que puede tener este término). El tenor de las reformas, si bien se realizan con una retórica anti-neoliberal o anti-mercado, resultan en una profundización del proceso previo en la medida que toma como uno de sus principales ejes a la competitividad, tanto la que logren los investigadores como la que permitan estos en su relación con otras instituciones de la sociedad. Hallamos definitivamente instalada una nueva lógica de pertinencia que ya no se encuentra en la trascendencia de la sociedad vigente, sino especialmente en su reproducción potenciada.

En definitiva, proponemos un ordenamiento que permita abordar de la manera más sencilla posible las prácticas diferenciales de los grupos en relación a las temáticas generales trabajadas en la presente tesis, evaluando las rupturas y continuidades de los rasgos históricos dentro de la universidad actual. Presentamos así cuatro grandes grupos que permiten organizar las prácticas universitarias según predominen rasgos y evidencias de: 
1) la persistencia y transformación del modelo humboldtiano (filosofía alemana)

2) la persistencia y transformación del modelo tradicional argentino (55-66)

3) la influencia de las reformas de mercado de primera generación (décadas del 80 y 90)

4) la influencia de las nuevas lógicas de competitividad y pertinencia social o reformas de mercado de segunda generación (a partir de 2001)

El objeto de esta segmentación se basa en observar cuáles son los elementos o características de la historia de la universidad que perduran en el tiempo y cuáles son aquellos que se han ido transformando en cada momento hasta llegar a la actualidad. En los dos primeros puntos estudiaremos los elementos que se observan como persistentes o transformados en los modelos de universidad humboldtiano y tradicional argentino en relación a la universidad actual. En los puntos 3 y 4 se discute esencialmente cuáles son los factores que más han influido en la conformación de un nuevo modelo de institución en Argentina, dividido en dos etapas que se diferencian en el transcurso de la tesis.

Además de la segmentación histórica, realizamos otra división que se relaciona con las áreas genéricas que agrupan los cambios en las formas y contenidos de la producción de conocimiento en la universidad argentina actual. Los temas que en esta investigación tomamos como prioritarios son:

- las demandas sociales y consecuencias de los nuevos atributos exigidos a la universidad y sus grupos

- las lógicas de actividad de los grupos de investigación y docencia

- la fusión, confusión y transformación de las funciones universitarias

- las políticas científicas y universitarias y sus consecuencias

- las articulaciones y relaciones con el medio

Estas temáticas, algunas de las cuales ya han sido abordadas por el PICTR00013, toman gran relevancia para los actores (académicos, políticos y teóricos) involucrados en la producción de conocimiento y, a su vez, son claros ejemplos donde se observan yuxtaposiciones, contraposiciones y enfrentamientos entre lógicas de actividad o acción.

\subsection{La disputa de modelos y lógicas dentro de la universidad: avance sobre su causa y reflexión sobre sus formas}

Las transformaciones producidas desde mediados del siglo XX generaron tensiones dentro de las instituciones científicas debido a las contradicciones entre las funciones tradicionales y las exigidas en la actualidad. La forma más general en que esto aparece es en el debate entre el modelo alemán y otro que propende a dar respuestas directas a las demandas provenientes de ámbitos socio-productivos. A su vez, dentro de este último se discute la necesidad de responder a demandas puramente económicas frente a la respuesta a demandas de grupos sociales minoritarios o marginados ${ }^{6}$.

Identificamos una contradicción interna que surge en los discursos de los diversos actores relacionados con la ciencia y la universidad y que es fuente de fuertes tensiones. Por un lado existe el consenso sobre la necesidad y la existencia de hecho de un científico libre y desligado de las restricciones a la que es sometido cualquier otro trabajador, sin embargo, por otro, también existe aceptación sobre las mejoras al bienestar social realizadas por el mismo científico a partir de sus aportes directos a la resolución de problemas sociales y, especialmente, a la reproducción ampliada del producto de un país. Esta contradicción logra desentrañarse a partir de la comprensión integrada (universal) de dos polos que aparecen como opuestos, pero que son parte de una misma problemática social. Este es el papel principal que cumple el estudio de las transformaciones de la ciencia como parte del movimiento de una rama o sub-sistema de la producción global.

Por tanto, uno de los aspectos claves del trabajo (y del cual soy consciente que falta indagar mucho aún) es el estudio del proceso - tanto a nivel práctico como de la consciencia social- a partir del cual ciencia y producción se influyen mutuamente y, principalmente, los esfuerzos por descifrar cómo la imbricación entre estas dos esferas altera las formas de hacer y pensar la ciencia. 
Si bien la incorporación de la ciencia al proceso productivo reviste larga data, en el trabajo se enfoca especialmente cómo, luego de la posguerra y de la mano del modelo lineal de innovación, las programaciones científicas comenzaron a tener una profunda dependencia del cálculo económico y, a partir de la década del setenta, se le anexa a esta característica la necesidad de interacción entre los actores directamente interesados en la creación de conocimiento (Estado-empresas/organizaciones sociales-universidad). Se genera así una fuente de tensiones irresolubles en las instituciones científicas, las cuales se transforman en ámbitos productores de valores de uso para otros.

A partir de la reflexión sobre estos conflictos y la diversidad de enfoques que buscan conceptualizarlos, recurrimos al valioso material empírico que resultan las entrevistas a los grupos de investigación y docencia universitarios realizadas por el PICTR00013. La directora del proyecto, al explicar el espíritu con que estas fueron elaboradas señala: "un tema central que nos preocupa es la tensión entre los roles tradicionales demandados para las funciones de docencia, investigación, transferencia y extensión frente al notorio aumento de las exigencias sociales, a consecuencia de la crisis y también por la no decidida intervención de las políticas públicas en ese espacio..." (Riquelme, 2008a; p.22).

Las entrevistas fueron efectuadas a grupos de las universidades nacionales de Buenos Aires, Mar del Plata y Misiones y, dado el objeto de la tesis, en nuestro análisis tomamos en cuenta a 101 de un total de 180 realizadas. Estas son las específicamente efectuadas a quienes consideraron a la investigación como una de sus actividades principales (a veces en forma exclusiva y otras en relación con la docencia o la extensión). Las entrevistas tuvieron como fin estudiar las relaciones y vinculaciones que las instituciones de educación superior tienen con su entorno local, con las empresas, con las organizaciones públicas y privadas de su territorio. A tal efecto su cuestionario semi-estructurado exploró los siguientes aspectos: - (i) cómo se produce genera y reproduce el conocimiento en el mundo académico, (ii) las vinculaciones al interior de la academia y con otros centros nacionales e internacionales- (iii) -las relaciones con el sector productivo, con el Estado y con organizaciones y ONGs gubernamentales (actividades de transferencia, extensión, consultorías, etc. ), así como los nuevos movimientos sociales emergentes y (iv) el papel de las redes entre investigadores, centros e institutos académicos nacionales e internacionales en el fortalecimiento de los grupos de trabajo de las universidades.

Puede observarse la relación directa entre las temáticas genéricas en que segmentamos el análisis de la universidad en esta tesis (definidas en el anterior apartado) y los principales lineamientos de las entrevistas que representan nuestra base empírica.

El análisis cualitativo se realizó con el aporte del programa atlas-ti, a partir del cual se hallaron frases representativas según temáticas genéricas, segmentadas además por universidad, facultades y por tipo de actividad predominante del grupo entrevistado. De esta forma avanzamos en la identificación de la predominancia de lógicas particulares según cada uno de estos segmentos. Sin embargo, no exponemos directamente las frases de los investigadores-docentes entrevistados, sino que se utilizan estas bases para sustentar el desarrollo interpretativo expuesto en el total de la tesis.

En definitiva, el estudio comparado de las entrevistas se inicia en la clasificación de los grupos a través de diferenciarlos según universidad, campo de conocimiento y tipo de actividad prioritaria que realizan. Luego se realiza un procesamiento cualitativo auxiliar para identificar sus vinculaciones y/o ocupaciones principales realizado a través del programa atlas-ti. Se finaliza con un análisis cualitativo detallado de los casos seleccionados en relación con los interrogantes planteados a lo largo de toda la tesis.

La interpretación de las entrevistas a la luz de las reflexiones realizadas en la tesis permite comprobar la creciente diferenciación de ideas y prácticas científico-académicas las que se traducen, a su vez, en importantes fusiones, confusiones y pleitos entre y por el carácter de las funciones que debe adoptar la universidad. Esto se observa en el creciente cuestionamiento a características fundamentales de la 
institución cuyo centro es la universalidad del saber. Hoy se pone en duda a la universidad, especialmente, como comunidad autónoma y espacio único de producción académico-científica, así como la ciencia en general ya no es vista como esfera crítica y capaz de trascender los límites de su sociedad. La disputa entre las lógicas no parecería estar siendo por el carácter del conocimiento, sino simplemente por su uso (su utilidad) y la consecuente fuente de poder que de ellas emana. Es en este sentido el conflicto no resulta una disputa por el ser de la universidad (por la idea de universidad), sino por su deber ser, discusión que la filosofía ilustrada demostró que no tiene fin en términos de la razón.

Parte 2

Las funciones de la universidad y los cambios en las prácticas de sus investigadores-docentes: sobre la multiplicidad de evidencias y enfoques existentes

En primer lugar hemos reconocido las rupturas y continuidades en el quehacer universitario que remitan a los agrupamientos planteados - modelo humboldtiano, modelo tradicional y reformas de mercado de primera y segunda generación-. En segundo lugar identificamos las grandes problemáticas de la universidad actual que orientan o sobredeterminan la producción de conocimiento - demandas sociales y consecuencias de los nuevos atributos exigidos a la universidad; lógicas de actividad de los investigadores-docentes; fusión, confusión y transformación de las funciones universitarias; políticas científicas y universitarias y sus consecuencias y articulaciones y relaciones con el medio-. El ejercicio que ahora desarrollamos resulta en un aporte para la reflexión sobre la diversidad de nociones a partir de las que se construyen las nuevas formas de pensar las funciones tradicionales de la universidad, tanto a nivel global como en Argentina?

\subsection{Aportes para la reflexión sobre las nuevas formas de pensar el rol de la ciencia y la universidad}

A fin de ordenar y dar luz a la diversidad de nociones sobre el rol de la ciencia y sus instituciones (especialmente la universidad), sistematizamos en una serie de cuadros las ideas, enfoques y teorías con las que hemos trabajado. La metodología busca descubrir las rupturas y continuidades de la universidad actual respecto a los dos modelos estilizados desarrollados en esta tesis (humboldtiano y tradicional argentino), así como las transformaciones provenientes de lo que llamamos primera y segunda generación de reformas de mercado (80-90 y 2001). También se mantienen las áreas genéricas que agrupan los cambios en las formas y contenidos en la producción de conocimiento de la universidad argentina actual en relación a sus antecedentes históricos (demandas sociales, lógicas de los grupos, funciones, política científica y articulaciones). En definitiva, partiendo de los discursos académicos, intentamos reconstruir las formas en que hoy se piensa a la ciencia y a la universidad en particular, dejando en claro cómo en la construcción de estas ideas se yuxtaponen categorías de distintos momentos y contextos históricos. Estas ideas o reflexiones podrían actuar a la manera de hipótesis sobre las prácticas de las instituciones y de los grupos de investigación y docencia.

En relación al modelo alemán clásico, se señalan especialmente transformaciones que han ocurrido sobre las lógicas de actividad de los grupos en la producción de conocimiento, las exigencias a las instituciones y el consecuente cambio de sus funciones. Repetidamente se encuentra entre los analistas de la educación superior la idea del "aislamiento" de sus instituciones, así como la necesidad responder a necesidades sociales concretas, ya sea desde la formación o la aplicación de investigaciones. Estas presiones se traducen en cambios en las formas que los investigadores y sus grupos producen conocimiento. Por último, también resulta interesante observar cómo se refleja en los grupos universitarios la crisis de legitimidad que algunos autores entienden viven hoy las instituciones científicas y de educación superior (Cuadro 3.3.1). 
Cuadro 3.3.1. Nuevas formas de pensar la ciencia y sus instituciones: rupturas y continuidades del modelo humboldtiano

\begin{tabular}{|c|c|c|c|}
\hline \multicolumn{4}{|c|}{ Rupturas y continuidades del modelo humboldtiano (filosofía alemana) } \\
\hline $\begin{array}{l}\text { Demandas sociales y } \\
\text { consecuencias de los } \\
\text { nuevos atributos } \\
\text { exigidos a la } \\
\text { universidad }\end{array}$ & \begin{tabular}{|l} 
Tesis del "aislamiento": se \\
acusa a la universidad de ser \\
una institución socialmente \\
aislada debido a que sus \\
actividades no son \\
directamente útiles (Autores \\
varios)
\end{tabular} & $\begin{array}{l}\text { Formación de profesionales en } \\
\text { resolución de problemas } \\
\text { concretos sin capacidad general } \\
\text { y sin posibilidades de } \\
\text { interactuar (T. Fanfani y } \\
\text { Gómez Campo) }\end{array}$ & \\
\hline $\begin{array}{l}\text { Lógicas de actividad } \\
\text { científica- } \\
\text { universitaria }\end{array}$ & $\begin{array}{l}\text { Crecimiento marcado de la } \\
\text { especialización dentro de las } \\
\text { disciplinas (Becher)/ } \\
\text { Profundización de la } \\
\text { división del trabajo dentro } \\
\text { de los grupos de } \\
\text { investigación (Hevly) }\end{array}$ & $\begin{array}{l}\text { Sobre el motor de la vida } \\
\text { académica: prestigio, elección } \\
\text { de vida, reproducción material, } \\
\text { vocación de servicio (Becher) }\end{array}$ & $\begin{array}{l}\text { Tecnificación del } \\
\text { conocimiento } \\
\text { científico (Lukacs, } \\
\text { Lefevre) }\end{array}$ \\
\hline $\begin{array}{l}\text { Sobre las funciones } \\
\text { universitarias }\end{array}$ & $\begin{array}{l}\text { Acciones derivadas de crisis } \\
\text { de legitimidad: ideario } \\
\text { social que se opone a ciertas } \\
\text { normas de funcionamiento } \\
\text { universitario (de Sousa } \\
\text { Santos) }\end{array}$ & $\begin{array}{l}\text { Reducción de la importancia } \\
\text { del saber por el saber mismo y } \\
\text { especialización en temáticas } \\
\text { particulares (Gibbons/Becher) }\end{array}$ & $\begin{array}{l}\text { Coexistencia de } \\
\text { nociones tradicionales } \\
\text { en la concepción de las } \\
\text { funciones, } \\
\text { especialmente en las } \\
\text { ciencias exactas } \\
\text { (PICTR00013) }\end{array}$ \\
\hline $\begin{array}{l}\text { Política científica y } \\
\text { sus consecuencias }\end{array}$ & $\begin{array}{l}\text { Instauración de líneas } \\
\text { prioritarias ajenas a la } \\
\text { realidad científica y social } \\
\text { (Varsavky / Oteiza) }\end{array}$ & $\begin{array}{l}\text { Generalización de la idea } \\
\text { respecto a que la ciencia debe } \\
\text { tener pertinencia social(autores } \\
\text { varios) }\end{array}$ & $\begin{array}{l}\text { Urgencia en las } \\
\text { necesidades de } \\
\text { respuesta que exige el } \\
\text { Estado como barrera } \\
\text { para conseguir los } \\
\text { logros que podría } \\
\text { brindar la universidad } \\
\text { (filosofía ilustrada } \\
\text { alemana) }\end{array}$ \\
\hline
\end{tabular}

El segundo grupo de reflexiones a la manera de hipótesis (Cuadro 3.3.2), se refiere al modelo que en este trabajo llamamos tradicional argentino. En este caso ya no se reflejan tanto los cambios ocurridos con dicho modelo, sino que se cuestiona cuáles son los elementos que persisten y cuáles los que han sido modificados. Por ejemplo, la idea sobre campo científico de Bourdieu estaría avalando la posibilidad de construir una institución autónoma tal como lo pensaron los actores del período 55-66. Otros elementos que formaban parte de la discusión sobre universidad en aquel momento histórico, son las dificultades de articulaciones entre la institución y diversidad de sectores (productivos, sociales, científicos del exterior) y la continuidad (o no) de las políticas llamadas cientificistas y sus consecuencias sobre la actividad de los grupos sus lógicas de creación de conocimiento. Finalmente, también reflexionamos sobre cuánto se respetan las nociones tradicionales de investigación y transferencia dentro de los grupos actuales. 
Cuadro 3.3.2. Nuevas formas de pensar la ciencia y sus instituciones: Rupturas y continuidades del modelo tradicional argentino

\begin{tabular}{|c|c|c|}
\hline \multicolumn{3}{|c|}{ Rupturas y continuidades del modelo tradicional argentino } \\
\hline $\begin{array}{l}\text { Demandas sociales y } \\
\text { consecuencias de los } \\
\text { nuevos atributos exigidos } \\
\text { a la universidad }\end{array}$ & $\begin{array}{l}\text { Presiones sociales mediatizadas } \\
\text { por las normas vigentes en el } \\
\text { campo científico (Bourdieu) }\end{array}$ & $\begin{array}{l}\text { Escasez cuantitativa de } \\
\text { investigación aplicada y poca } \\
\text { relación con asuntos básicos de la } \\
\text { región (Herrera) }\end{array}$ \\
\hline $\begin{array}{l}\text { Lógicas de actividad } \\
\text { científica-universitaria }\end{array}$ & $\begin{array}{l}\text { La incidencia de la interdisciplina } \\
\text { en la transformación de objetos } \\
\text { de estudio resulta baja debido a la } \\
\text { dificultad de transformación de } \\
\text { las estructuras tradicionales } \\
\text { (Rhoten) / Procesos de } \\
\text { elitización y control ideológico } \\
\text { que perpetúan estructuras } \\
\text { disciplinares (Becher) }\end{array}$ & $\begin{array}{l}\text { Desconexión entre las actividades } \\
\text { de investigación y docencia } \\
\text { (Becher/Riquelme/PICTR00013) }\end{array}$ \\
\hline $\begin{array}{l}\text { Sobre las funciones } \\
\text { universitarias }\end{array}$ & $\begin{array}{l}\text { Desaparición de la planificación } \\
\text { de las actividades universitarias } \\
\text { en torno a los problemas de } \\
\text { desarrollo del país (Frondizi) }\end{array}$ & $\begin{array}{l}\text { Transferencia concebida como } \\
\text { formación de profesionales y } \\
\text { técnicos y creación de } \\
\text { conocimiento para que su } \\
\text { aplicación sea realizada por } \\
\text { instituciones distintas a la } \\
\text { universidad (Frondizi) }\end{array}$ \\
\hline $\begin{array}{l}\text { Política científica y sus } \\
\text { consecuencias }\end{array}$ & $\begin{array}{l}\text { Predominancia de políticas } \\
\text { implícitas que no cuestionan } \\
\text { estructuras de dependencia } \\
\text { fundamentales (Herrera) / } \\
\text { Ampliación de brecha científica } \\
\text { por importación de políticas de } \\
\text { CyT (Oteiza) }\end{array}$ & $\begin{array}{l}\text { Creación de un mercado } \\
\text { científico a partir de la aplicación } \\
\text { de políticas de carácter } \\
\text { cientificista (Varsavsky) }\end{array}$ \\
\hline $\begin{array}{l}\text { Articulaciones y } \\
\text { relaciones con el exterior }\end{array}$ & $\begin{array}{l}\text { Integración aislada (y } \\
\text { dependiente) de instituciones } \\
\text { locales con triángulos integrados } \\
\text { del exterior (Sábato) }\end{array}$ & $\begin{array}{l}\text { Dependencia cultural completa } \\
\text { del cientificista en un país } \\
\text { subdesarrollado (Varsavsky) }\end{array}$ \\
\hline
\end{tabular}

El cuadro 4.3.3 resume algunas problemáticas que se fueron incorporando al funcionamiento de las universidades durante las décadas del ochenta y noventa. Como es dable suponer, todas ellas se refieren a la incorporación de criterios de mercado a las lógicas académicas y científicas. Volvemos a remarcar que de ninguna manera entendemos que las indicadas son todas las reformas ocurridas en esta época, sino que son algunas de las cuestiones que, estimamos, pueden estar influyendo fuertemente en las lógicas actuales de producción y circulación de conocimiento dentro de la universidad. 
Cuadro 3.3.3. Nuevas formas de pensar la ciencia y sus instituciones: Influencia de las reformas neoliberales de las décadas del 80 y 90

\begin{tabular}{|c|c|c|c|}
\hline \multicolumn{4}{|c|}{ Influencia de las reformas de mercado (80s y 90s) } \\
\hline $\begin{array}{l}\text { Demandas sociales y } \\
\text { consecuencias de los } \\
\text { nuevos atributos } \\
\text { exigidos a la } \\
\text { universidad }\end{array}$ & $\begin{array}{l}\text { Atención a demandas como } \\
\text { argumento discursivo para } \\
\text { mejorar legitimidad social, } \\
\text { pero que no se condice } \\
\text { totalmente con las actividades } \\
\text { de los grupos } \\
\text { (Bourdieu/Becher) }\end{array}$ & $\begin{array}{l}\text { Las empresas ya no sólo } \\
\text { quieren que el } \\
\text { conocimiento básico sea } \\
\text { brindado por la } \\
\text { universidad, sino también } \\
\text { su aplicación a la } \\
\text { producción: se transforma } \\
\text { el llamado "modelo lineal" } \\
\text { de innovación (Vence } \\
\text { Deza) }\end{array}$ & $\begin{array}{l}\text { Atención a demandas } \\
\text { inmediatas y particulares y } \\
\text { falta de respuesta a demandas } \\
\text { sociales críticas (Riquelme) }\end{array}$ \\
\hline $\begin{array}{l}\text { Lógicas de actividad } \\
\text { científica- } \\
\text { universitaria }\end{array}$ & $\begin{array}{l}\text { Las pedagogías orientadas al } \\
\text { mercado trasladan el poder del } \\
\text { control simbólico del Estado a } \\
\text { los agentes económicos } \\
\text { (Bernstein) }\end{array}$ & $\begin{array}{l}\text { La competencia como uno } \\
\text { de los factores explicativos } \\
\text { del incremento de la } \\
\text { especialización (Becher) }\end{array}$ & $\begin{array}{l}\text { Elección de estrategias de } \\
\text { investigación a través líneas } \\
\text { o necesidades de } \\
\text { financiamiento y su correlato } \\
\text { en determinación de } \\
\text { temáticas (autores varios) }\end{array}$ \\
\hline $\begin{array}{l}\text { ciones } \\
\text { s }\end{array}$ & $\begin{array}{l}\text { Nuevas funciones de la } \\
\text { universidad: formación de } \\
\text { profesionales que resuelvan } \\
\text { problemas técnicos; } \\
\text { acreditación conocimientos; } \\
\text { creación de grupos mixtos de } \\
\text { expertos (Gibbons) / Creación } \\
\text { de jerarquías ligadas al } \\
\text { proceso económico } \\
\text { (Becher/Hevly) }\end{array}$ & $\begin{array}{l}\text { Valores principales de la } \\
\text { universidad: conectividad } \\
\text { y eficiencia en la } \\
\text { transferencia de } \\
\text { conocimientos (Gibbons) }\end{array}$ & $\begin{array}{l}\text { Se traspone continuamente } \\
\text { las categorías extensión, } \\
\text { transferencia y vinculación y } \\
\text { se impone una lógica de } \\
\text { brindar servicios (en general } \\
\text { rutinarios) como forma de } \\
\text { responsabilidad social (de } \\
\text { Sousa Santos) / El término } \\
\text { vinculación cobra } \\
\text { importancia por encima de } \\
\text { las antiguas funciones de } \\
\text { extensión y transferencia } \\
\text { (PICTR00013) }\end{array}$ \\
\hline $\begin{array}{l}\text { Política científica y } \\
\text { sus consecuencias }\end{array}$ & $\begin{array}{l}\text { Caída de legitimidad y } \\
\text { recuperación a través de } \\
\text { sistemas de evaluación externa } \\
\text { (Gibbons) }\end{array}$ & $\begin{array}{l}\text { Adaptación de } \\
\text { conocimientos a partir de } \\
\text { solucionar fallas de canales } \\
\text { de información con el } \\
\text { exterior (Banco Mundial/ } \\
\text { Stiglitz) }\end{array}$ & $\begin{array}{l}\text { Procesos de privatización y } \\
\text { mercantilización a partir de } \\
\text { políticas nacionales } \\
\text { específicas (varios autores) }\end{array}$ \\
\hline $\begin{array}{l}\text { Articulaciones y } \\
\text { relaciones con el } \\
\text { exterior }\end{array}$ & $\begin{array}{l}\text { Los intereses de los agentes de } \\
\text { control simbólico } \\
\text { universitarios resultan } \\
\text { opuestos al de los mismos } \\
\text { agentes pero en la esfera de la } \\
\text { producción (Bernstein) }\end{array}$ & $\begin{array}{l}\text { Baja investigación } \\
\text { experimental como forma } \\
\text { de expresar debilidad de } \\
\text { vínculos con sectores } \\
\text { productivos e innovadores } \\
\text { (Albornoz) }\end{array}$ & $\begin{array}{l}\text { Habilitación de las } \\
\text { universidades para actuar } \\
\text { como laboratorios I+D de } \\
\text { empresas y abaratar sus } \\
\text { costos } \\
\text { (Riquelme/PICTR00013) }\end{array}$ \\
\hline
\end{tabular}

Finalmente el cuadro 3.3.4 avanza en la resolución de uno de nuestros principales cuestionamientos respecto a la universidad argentina actual: si bien se ha cambiado el discurso típicamente neoliberal sobre las instituciones científicas y académicas, la pregunta es si efectivamente la lógica implícita respecto a cómo se piensan dichas instituciones se ha transformado. De allí que nos interese, utilizando las ideas actuales de diversos autores, observar su cumplimiento o no en los acciones concretas de los universitarios en Argentina. 
Cuadro 3.3.4. Nuevas formas de pensar la ciencia y sus instituciones: Influencia de las nuevas lógicas de competitividad o pertinencia social

\begin{tabular}{|c|c|c|c|}
\hline \multicolumn{4}{|c|}{ Influencia de las nuevas lógicas de competitividad o pertinencia social (a partir de 2001) } \\
\hline $\begin{array}{l}\text { Demandas sociales y } \\
\text { consecuencias de los } \\
\text { nuevos atributos } \\
\text { exigidos a la } \\
\text { universidad }\end{array}$ & $\begin{array}{l}\text { Imposibilidad de gran } \\
\text { cantidad de sectores para } \\
\text { revelar sus demandas sociales } \\
\text { y productivas y consecuente } \\
\text { dominio de quienes poseen } \\
\text { mayores recursos económicos } \\
\text { (Riquelme) }\end{array}$ & $\begin{array}{l}\text { Mayoría de demandas } \\
\text { adaptativas y de poca } \\
\text { originalidad científica } \\
\text { (Iñigo Carrera) }\end{array}$ & $\begin{array}{l}\text { Elección de temáticas de } \\
\text { investigación de acuerdo a } \\
\text { una sobredeterminación de } \\
\text { la atención a demandas del } \\
\text { sector productivo } \\
\text { (PICTR00013) }\end{array}$ \\
\hline $\begin{array}{l}\text { Lógicas de actividad } \\
\text { científica- } \\
\text { universitaria }\end{array}$ & $\begin{array}{l}\text { Interdisciplina como } \\
\text { entrenamiento creativo para la } \\
\text { resolución de problemas } \\
\text { concretos y como forma } \\
\text { transformadora de pensar los } \\
\text { problemas del conocimiento } \\
\text { (Gibbons, Boix Mansilla y } \\
\text { Gardner, Rhoten) }\end{array}$ & $\begin{array}{l}\text { Creación de una nueva } \\
\text { lógica de producción de } \\
\text { conocimiento } \\
\text { pluriuniversitaria o } \\
\text { traspaso del modo } 1 \text { al } \\
\text { modo } 2 \text { (de Sousa Santos / } \\
\text { Gibbons) }\end{array}$ & $\begin{array}{l}\text { Elección de temáticas de } \\
\text { investigación a fin de } \\
\text { lograr mayores } \\
\text { posibilidades de } \\
\text { publicación y } \\
\text { transferencias (Becher) / } \\
\text { Transformación del interés } \\
\text { por el saber: centralidad en } \\
\text { la disputa por su uso } \\
\text { (Carnoy/Naishtat) }\end{array}$ \\
\hline $\begin{array}{l}\text { Sobre las funciones } \\
\text { universitarias }\end{array}$ & $\begin{array}{l}\text { Autonomía vs. criterios } \\
\text { económicos (autores varios) }\end{array}$ & $\begin{array}{l}\text { Acciones derivadas de } \\
\text { crisis de hegemonía: } \\
\text { confusión de funciones } \\
\text { derivada de idearios } \\
\text { externos a la universidad } \\
\text { (de Sousa Santos) }\end{array}$ & $\begin{array}{l}\text { La investigación básica se } \\
\text { realiza en función de una } \\
\text { potencial aplicación. La } \\
\text { investigación, ahora es } \\
\text { investigación y aplicación } \\
\text { (I+D) (Salomon/Elzinga) }\end{array}$ \\
\hline $\begin{array}{l}\text { Política científica y } \\
\text { sus consecuencias }\end{array}$ & $\begin{array}{l}\text { Incremento de los fondos que } \\
\text { se centralizan y se destinan a } \\
\text { temas cada vez más } \\
\text { específicos y con potenciales } \\
\text { aplicaciones (Hevly)/ Quien } \\
\text { ingresa en esa lógica logra } \\
\text { acumular cada vez más } \\
\text { prestigio y recursos (Becher) }\end{array}$ & $\begin{array}{l}\text { Políticas marcadas por } \\
\text { fuerte economicismo que } \\
\text { actúan en detrimento de las } \\
\text { lógicas académicas y en } \\
\text { grupos sociales de menor } \\
\text { poder (Dagnino) }\end{array}$ & $\begin{array}{l}\text { Contradicción entre mayor } \\
\text { pertinencia social y } \\
\text { avances de lógicas de } \\
\text { privatización del } \\
\text { conocimiento (de Sousa } \\
\text { Santos) }\end{array}$ \\
\hline $\begin{array}{l}\text { Articulaciones y } \\
\text { relaciones con el } \\
\text { exterior }\end{array}$ & $\begin{array}{l}\text { Integración subordinada y } \\
\text { "conocimientos aplicables no } \\
\text { aplicados" (Kreimer) / } \\
\text { Debilidades en la relación } \\
\text { entre las universidades centro- } \\
\text { periferia del país a partir de la } \\
\text { reproducción de la relación } \\
\text { con los centros del exterior } \\
\text { (PICTR00013). }\end{array}$ & $\begin{array}{l}\text { Objeto de la articulación } \\
\text { de grupos universitarios: } \\
\text { Hay un predominion de } \\
\text { intercambio de } \\
\text { información más que de } \\
\text { creación de nuevo } \\
\text { conocimiento (Rhoten) }\end{array}$ & $\begin{array}{l}\text { Quienes motorizan las } \\
\text { actividades } \\
\text { interdisciplinarias son los } \\
\text { grupos más nuevos (y } \\
\text { dentro de los antiguos, los } \\
\text { integrantes jóvenes), } \\
\text { quienes buscan así romper } \\
\text { con estructuras de reparto } \\
\text { de recursos que los } \\
\text { perjudican (Rhoten/ } \\
\text { Becher) }\end{array}$ \\
\hline
\end{tabular}

\section{Parte 3}

\section{La producción y circulación de conocimiento científico: reflexión sobre las rupturas y continuidades de la idea de universidad en Argentina}

Presentamos ahora la síntesis del proceso de reflexión sobre la idea de universidad que desarrollamos a lo largo de la tesis. Nuestro objeto es observar cómo las transformaciones tanto de la estructura económico-social, como de las políticas y del discurso académico, se reflejan en las prácticas concretas de los investigadores-docentes que trabajan en las universidades. Para ello utilizamos el 
material empírico proveniente de una selección de entrevistas realizadas en el marco del Proyecto PICT Redes "Las Universidades frente a las demandas sociales y productivas. El rol promotor y la capacidad de intervención. Las respuestas de reorientación y cambio curricular" (PICTR00013), a partir de las cuales realizamos una serie de inferencias que revelan las rupturas y continuidades históricas existentes en las actividades actuales de los universitarios.

Con este objeto se han seleccionado una serie de entrevistas realizadas por el PICTR00013 a grupos de investigación y docencia de tres universidades públicas del país (Buenos Aires, Mar del Plata y Misiones) que trabajan en distintas disciplinas o campos de conocimiento. En el análisis de las entrevistas se las segmentó según la actividad que los grupos decían priorizar, ya fuera investigación, docencia, extensión, transferencia o alguna combinación entre estas funciones. En el caso de la presente tesis, se tomaron en cuenta sólo las entrevistas de grupos que tenían dentro de sus actividades principales a la investigación. Por tanto, trabajamos con grupos que se auto-definieron en algunos casos como grupos de investigación pura (I) y, en otros, como de investigación orientada a la aplicación o extensión (I+E) y de investigación complementada con docencia $(\mathrm{I}+\mathrm{D})^{8}$. Si bien los grupos seleccionados son denominados I o I+E, ello no implica que no cumplan con tareas de docencia o que, por ejemplo, los grupos I no efectúen en absoluto labores de transferencia. El objeto es observar las diversas formas de entender las funciones universitarias - investigación, docencia, extensión y transferencia- según esta segmentación. A su vez, se busca identificar y comparar las principales prácticas e ideas existentes en distintos campos o áreas de conocimiento, así como en las facultades y universidades de procedencia de los entrevistados ${ }^{9}$.

A partir del desarrollo de la tesis han surgido gran cantidad de aspectos en que los cambios estructurales en la idea de universidad afectaron a las prácticas concretas de los investigadores y docentes que la conforman. A través del seguimiento de diversidad de autores y de la influencia de los procesos económicos y políticos, encontramos distintas nociones referentes a estos últimos cambios. Avanzamos en este capítulo sobre el análisis respecto a cómo se traducen estos movimientos en la universidad argentina, así como también en la comprensión de la diversidad de elementos surgidos en distintos momentos históricos que actualmente son partes de la institución y se materializan en las actividades de sus investigadores y docentes.

Más allá de la interpretación propia de los cambios observados en las universidades, la percepción que sobre ellos tienen los propios investigadores resulta importante debido a que las transformaciones en las prácticas no sólo pasan por un cambio de orientación en las políticas científicas y universitarias, sino también (y principalmente) por una profunda mutación en lo que se denomina idea de universidad, tanto dentro como fuera de la institución. Es decir, los cambios implicarían un nuevo "sentido común" respecto a lo que es la universidad y, fundamentalmente, a cuál debe ser su función dentro de la sociedad.

\subsection{Rupturas y continuidades del concepto de ciencia y universidad (idea de universidad) en la actualidad}

A partir de la sistematización de ideas, enfoques y teorías realizada, avanzamos ahora en la indagación sobre los procesos que conforman la lógica de producción de conocimiento de la universidad actual. La particularidad con que se los presenta es la de indicar si estos implican una ruptura o continuidad directa con los patrones estilizados construidos para distintos momentos históricos. Lograremos así cumplir con el objetivo de identificar la diversificación de nociones y lógicas (muchas veces opuestas) que componen a la universidad argentina de los últimos años.

El análisis será realizado diferenciando la discusión según los modelos estilizados construidos para distintos momentos de la historia de la universidad argentina. Esto facilitará el objetivo de comprender las rupturas y continuidades de la institución actual respecto a la existente en cada tiempo histórico señalado.

Revista HISTEDBR On-line, Campinas, n.39, p. 4-31, set.2010 - ISSN: 1676-2584 
De esta forma identificamos cuatro grandes períodos históricos de análisis que den cuenta de los cambios en las prácticas de los investigadores-docentes:

1) Rupturas y continuidades del modelo humboldtiano

2) Rupturas y continuidades del modelo tradicional argentino

3) Influencia de las reformas de mercado (80s y 90s)

4) Influencia de las nuevas lógicas de competitividad o pertinencia social (a partir de 2001)

En cada uno de estos períodos nos centraremos en cinco grandes grupos temáticos que orientan o sobredeterminan la producción de conocimiento ${ }^{10}$ :

a. Demandas sociales y consecuencias de los nuevos atributos exigidos a la universidad

b. Lógicas de actividad científica-universitaria

c. Sobre las funciones universitarias

d. Política científica y sus consecuencias

e. Articulaciones y relaciones con el exterior

Utilizamos como fuente del estudio de los procesos de trabajo y las lógicas de producción de conocimiento de los investigadores-docentes universitarios a la totalidad de entrevistas realizadas por el PICTR00013 de quienes entendieron que una de sus actividades predominantes es la investigación (I, I+D e I+E).

\subsubsection{Rupturas y continuidades del modelo humboldtiano en la universidad actual}

Tomando en cuenta los rasgos del modelo humboldtiano observamos, en primera medida, una ruptura muy clara con la universidad actual generada fundamentalmente por las nuevas demandas sociales a las que está expuesta la institución. En primer lugar, encontramos muy difundido la idea del "aislamiento" de la universidad, lo cual en general es asumido como el resultado de la concepción de ciencia de la filosofía alemana donde predomina la auto-reflexión del investigador. De esta forma, se suele contraponer a la "universidad-isla" con una institución conformada para responder eficientemente a las demandas directas de la sociedad. Seguramente por ello es que este discurso aparece más en los grupos que se autodenominan como I+E, quienes entienden que haría falta una "mayor presencia de la universidad en el medio" y denuncian "una tradición de pensar que la universidad es una caja de cristal", transformándose esto en una "mancha histórica" que acota la posible receptividad de la sociedad.

Este discurso parece hacerse eco de lo expuesto por varios de los autores que acusan a la universidad de ser una institución socialmente aislada debido a que sus actividades no parecieran ser directamente útiles (aplicables) (Gibbons, 1997 y 1998). De esta forma, la ciencia básica comienza a ser vista como un gasto ineficiente o, en el mejor de los casos, como una excentricidad o lujo propio del primer mundo. La forma de terminar de ser una "isla" es para muchos de los entrevistados la adopción de medidas necesarias para que se "extiendan los desarrollos básicos hasta su aplicación social o desarrollo tecnológico". Es habitual encontrar este tipo de argumentos en las facultades con mayor sesgo tecnológico (Ingeniería, Agronomía), aunque también predomina en las Humanidades y Ciencias Sociales y de Ciencias de la Salud.

También afectada por los nuevos atributos exigidos a la universidad por parte de la sociedad resulta la formación de los profesionales, donde lo que se propone es el entrenamiento en la resolución de problemas concretos por sobre la idea del modelo humboldtiano de impartir especialmente conocimientos generales y el fomento de la investigación en los alumnos de grado (T. Fanfani y Gómez Campo, 1989; Gibbons, 1998). Esta visión predomina especialmente en las Ciencias Económicas, cuyos entrevistados las consideraron de un algún modo superiores en relación al resto de las ciencias sociales a partir de su "mayor anclaje con la realidad".

Sin embargo, si bien podría aducirse que esta situación es propia de facultades que forman prioritariamente profesionales, la salida laboral y la relación de los contenidos con las demandas de mercado también resultaron una preocupación por parte de carreras mayormente científicas 
(especialmente en Misiones y Mar del Plata), donde se propuso incluso que las carreras que no tuvieran una mirada sobre el mercado de trabajo caían en el problema de formar graduados que se transforman en "entelequias disociadas de la realidad".

En cuanto a las lógicas de producción de conocimiento, poco tienen que ver con aquella expuesta en Alemania durante siglo XVIII donde la ciencia necesariamente debía tener un espíritu filosófico de totalidad. Hoy se le contrapone un marcado crecimiento de la especialización dentro de las disciplinas (Becher, 2001) y la tecnificación del conocimiento científico (Lukacs, 1985; Lefevre, 2005). Especialmente en aquellas unidades con mayor cercanía a las fronteras de conocimiento, los entrevistados han postulado "la imposibilidad de abarcar el total del conocimiento de un campo", ante lo cual el incremento de la especialización resulta la solución más simple y natural. A su vez, muchos de los grupos especialmente de los campos de las ciencias exactas y naturales y de las ciencias de la salud relacionaron su actividad diaria con "la realización de aplicaciones, el estudio de técnicas y el moldeo de tácticas o correlaciones para diagnósticos".

En relación a la concepción sobre las funciones universitarias, del modelo humboldtiano sólo vemos persistir aisladamente (especialmente en algunos sectores dedicados a la investigación de las facultades de ciencias exactas y naturales) el interés por la creación de conocimiento original, más allá de su aplicación directa (PICTR00013) ${ }^{11}$. Especialmente los grupos auto-denominados I en este campo, dieron cuenta de su imposibilidad práctica para dedicarse a crear conocimiento original a la par de la realización de aplicaciones tecnológicas o alguna otra implementación.

A partir de aquí todo lo que hallamos son rupturas con el modelo humboldtiano, donde especialmente se aprecia lo que de Sousa Santos (2005) describe como "crisis de legitimidad" del tradicional ideario social universitario. El estado de reflexión del científico o desarrollo de su intelectualidad ya no es bien visto. Incluso se llega a decir que "el pensar es sólo un juego intelectual" y la aplicación concreta es lo que realmente reporta utilidad a la sociedad. Más aún se relaciona al estado de reflexión (o autoreflexión) del científico con un "academicismo que lo mantiene aislado de la sociedad".

La crisis ocurre en forma generalizada y así también es como se ha extendido el discurso con la noción neoclásica de equidad, por la cual la justicia (social) se representa a partir de que cada uno pague por lo que recibe (Friedman y Friedman, 1993). En las distintas universidades y áreas de conocimiento, hubo investigadores-docentes que justificaban sus labores de extensión a partir de "devolver el favor que la sociedad me hizo al financiarme los estudios universitarios".

El resultado de los movimientos descriptos es que se tornan reales las descripciones realizadas por Gibbons (1997 y 1998) respecto a la especialización en temáticas particulares y la reducción de la importancia del saber por el saber mismo. Claro está que, a diferencia del citado autor, lo que debemos notar es que este proceso es el resultado de un desarrollo histórico particular que ha determinado un sendero de transformación de la ciencia. Esto no indica que la ciencia debe transformarse en esta dirección, sino sólo que lo ha hecho. Si esta situación la transformamos en teoría, la naturalizamos y la extendemos a cualquier tipo de sociedad, entonces lo que se pretende es realizar una apología del statu quo.

Muchas veces estas nociones apologéticas se transforman en imperativos sociales. En nuestro caso, este imperativo es el de la pertinencia social de la ciencia (ver p.e. Vessuri, 1998 y de Sousa Santos, 2005) y en nombre de este cada investigador o grupo justifica su accionar tomando para sí una definición propia y, casi seguro, distinta a la que adopta el otro (Bourdieu, 2003). En todas las unidades académicas se halla el discurso por el cual la ciencia no puede legitimarse autónomamente, sino a través de "su impacto en el desarrollo de la sociedad", ya sea a través de su inserción en sectores de la producción o para asistir a grupos sociales marginados o de menores recursos.

Haciéndose eco de este discurso, el Estado a través de su política científica cae en las intromisiones de las que ya nos habían prevenido los filósofos alemanes (Humboldt, 1959 Fichte, 1959). Los propios investigadores-docentes dan cuenta de cómo la urgencia en las necesidades de respuesta que exige el

Revista HISTEDBR On-line, Campinas, n.39, p. 4-31, set.2010 - ISSN: 1676-2584 
Estado actúa como barrera para conseguir mayores logros que podría brindar la universidad. Las actividades de muchos de los entrevistados dijeron ser detenidas o distraídas a partir de las presiones provenientes del sector político para que los científicos participen de sus planes de política social. Esto provoca el desvío hacia actividades rutinarias que podrían ser desarrolladas por funcionarios o técnicos con un mínimo de capacitación. Son una clara realidad las disrupciones internas que se crean dentro de las instituciones universitarias a partir de la diversidad de objeto que la ciencia tiene para un funcionario político y para un científico. Parte de la fragmentación y diferenciación entre instituciones, campos de conocimiento y grupos de investigación y docencia ocurre a partir de cuál de las dos posiciones es la predominante.

Más aún, el afán estatal por mostrarse permeable a estos imperativos ha tenido una serie de correlatos no necesariamente buscados. La instauración de líneas prioritarias ajenas a la realidad científica y social (Varsavsky, 1968 Oteiza, 1992 y 1996) es un ejemplo de ello, ya que una evidencia clara es que muy pocos investigadores universitarios demostraron estar trabajando en alguna de estas líneas, por más que para la obtención de subsidios así lo digan.

\subsubsection{Sobre las rupturas y continuidades del modelo tradicional argentino en la universidad actual}

Evaluamos ahora las nociones y prácticas en la universidad actual en relación a los rasgos de lo que llamamos el modelo tradicional de la universidad argentina, construido durante el período 1955-1966. A fin de mantener el orden de la exposición iniciamos la evaluación a partir de las consecuencias que las demandas actuales tienen sobre la universidad en relación a la continuidad o rupturas con las características de la institución durante el mencionado período.

La pregunta que nos realizamos frente al efecto de las demandas sociales es si, tal como sucedió con las rasgos del modelo humboldtiano, los correspondientes al que ahora estudiamos han sido alterados en la actualidad. Al menos en la retórica, actualmente se sigue manteniendo un discurso propio del modelo lineal de investigación vigente en las décadas del cincuenta y sesenta (Bush, 1999), donde supuestamente la universidad se mantiene autónoma y logra soportar las presiones sociales. Esta idea se asemeja mucho a lo que sostienen Bourdieu (2003) y Becher (2001) respecto a la mediatización de las determinaciones sociales por parte de las normas vigentes en el campo científico. En muchos casos esto fue avalado por los investigadores cuando se los consultó sobre cómo definían sus actividades y si las políticas estatales interferían en sus decisiones. En este nivel nos encontramos con una importante contradicción donde se declara la existencia de, por ejemplo, líneas prioritarias, pero a la vez la poca necesidad de seguirlas o, en otros casos, la existencia de una flexibilidad tal que cualquier investigador puede considerar su tema como dentro de las prioridades del Estado o Universidad.

También notamos que se ha sostenido una característica no deseable de aquellos tiempos como es la escasez cuantitativa de investigación aplicada y la poca relación con los asuntos básicos de la región, denunciada en los setenta por Herrera (1974) y en la actualidad por Albornoz (2002). Entre los discursos de los entrevistados, esta situación se interpreta de distintas maneras. Entre los grupos I+E se habla especialmente de la poca importancia que el científico le da las tareas aplicadas. Pero también en las universidades radicadas en las provincias hubo quienes denunciaron que los programas de investigación orientada se articulan desde la Ciudad de Buenos Aires y no reflejan (ni conocen) la realidad de las provincias. En ningún caso se reflexionó sobre la escasa demanda de tecnología por parte del sector productivo debido a la estructura económica subdesarrollada del país y menos aún sobre la dificultad que le puede provocar a un investigador-docente universitario ejecutar una política social en reemplazo de un Estado ausente. Sólo en algún caso aislado se pensó a la universidad como espacio de creación de un plan de desarrollo y no de ejecución; cuestión que representa una importante ruptura con el modelo tradicional (Riquelme y Langer, 2008).

Otro elemento que encontramos se ha sostenido en el tiempo es la baja incidencia de nuevas tendencias - como por ejemplo la interdisciplina- en la transformación de los objetos de estudio de los grupos universitarios. Tal como lo señala Rhoten (2003) los entrevistados han mencionado la dificultad de la transformación de las estructuras tradicionales como uno de los elementos claves en 
esta situación, especialmente en la dificultad que se tiene desde las estructuras político-administrativas para pensar campos de conocimiento más amplios y disímiles a los tradicionalmente existentes.

La constancia de las estructuras tradicionales también se relaciona con procesos de elitización y control ideológico que perpetúan estructuras disciplinares que, en su momento, había denunciado Oscar Varsavsky como propio del cientificismo y que hoy también encontramos, por ejemplo, en el estudio de Tony Becher sobre universidades en Estados Unidos. Varios entrevistados de las distintas universidades han relacionado la diferenciación entre grupos a partir de "la habilidad de saber recorrer los caminos que hay que recorrer en estos sistemas", lo cual especialmente en la UBA y la UNMdP se lo relacionó con el sistema de incentivos.

Se observa como una ruptura a la creciente desconexión existente entre las actividades de investigación y docencia (Becher, 2001; Riquelme, 2003 y 2008). De los dichos de los entrevistados se nota que gran parte de esta situación deriva de la escasez de universitarios con dedicaciones exclusivas (es decir, con tiempo y capacidad para investigar y practicar la docencia), así como las falencias tanto a nivel cuali como cuantitativo de los posgrados (especialmente doctorados).

Otro de los importantes rasgos hoy desaparecidos del modelo tradicional es el de la planificación de las actividades universitarias en torno a los problemas de desarrollo del país (Frondizi, 1971). Esto se ve reflejado en las entrevistas a partir de los comentarios sobre improvisación en las políticas universitarias, así como en la toma decisiones por parte de los investigadores-docentes. La falta de programación es denunciada tanto para la investigación como para la extensión y transferencia, donde se suelen crear proyectos o programas aislados y dependientes de redes personales que sólo representan pérdidas de recursos para la universidad, aunque en muchos casos resultan redituables para quien los haya organizado.

En general, se ha declarado que las políticas existentes, si bien explícitamente promueven la aplicación y la transferencia de tecnología, implícitamente no modificaron mucho su criterio respecto a épocas pasadas, en tanto en las evaluaciones académicas no se contempla la transferencia. De esta forma parecería que esta última actividad queda para quien "le guste ganar plata fácil". En otras palabras, a pesar de todas las políticas oficiales que enarbolan las banderas de la vinculación de la universidad y la sociedad y la necesidad de aplicar los conocimientos científicos, en los hechos la mayor parte de quienes desarrollan estas tareas son vistos como investigadores de segunda clase (especialmente en las facultades de ciencias exactas y naturales).

Paradójicamente, si bien hoy reina un clima de búsqueda de aplicación y donde el universitario tiene un discurso en que su actividad aparece inserta en la sociedad y da respuesta a sus necesidades directas, la política científica sigue teniendo fuertes rasgos cientificistas (Varsavsky, 1994), donde "las infinitas instancias de evaluación y de concurso y re concurso hacen que uno esté más preocupado por generar papers y competir que por generar grupos de trabajo cuya motivación esté en los resultados reales a conseguir que por esta dinámica que impone la política científica".

Y tal como Varsavsky exponía siguen encontrándose rastros de dependencia cultural completa del cientificista en un país subdesarrollado donde, salvo en el caso de muy pocos grupos de gran prestigio, la participación cada vez más asidua en redes internacionales de trabajo ubica a los grupos nacionales a trabajar con objetivos pre-fijados y en actividades específicas aisladas de su totalidad. Así es como luego de más de cincuenta años perduran las integraciones aisladas (y dependientes) de grupos científicos locales con triángulos integrados del exterior (Sabato y Botana, 1968), donde el investigador nacional participa en pos de lograr el codiciado paper en una revista internacional. Se reproducen, entonces, relaciones del tipo centro-periferia entre universidades locales y del exterior, lo cual a su vez genera mayores dificultades para la articulación entre universidades al interior del país (Riquelme, 2008b).

En este sentido parece mantenerse vigente la conclusión de Herrera (1974) respecto a la predominancia de políticas implícitas que no cuestionan estructuras de dependencia fundamentales. 
Especialmente quienes se dedican a las ciencias humanas ven a la ciencia como "un aparato autoreproductivo internacional, de reproducción de categorías y modos de experimentación". Por el contrario, desde las ciencias exactas y naturales y en muchos casos desde las ciencias de la salud y algunas áreas tecnológicas, se ve con desprecio a quienes actúan alejados de los centros mundiales de conocimiento. Claro está que esto es parte constitutiva de las tensiones internas no resueltas de la universidad.

\subsubsection{Influencia de las reformas de mercado de las décadas del ochenta y noventa en la universidad actual}

En este sub-apartado se reflexiona sobre cuáles son los principales rasgos que la universidad ha heredado de las reformas llevadas adelante en las décadas del ochenta y noventa en lo que se refiere a los procesos de producción de conocimiento.

En el desarrollo de la tesis observamos una de las características más notorias de esta etapa es la transformación del modelo lineal de innovación a manos de un sistema mayormente regido por la demanda de mercado. En este marco las empresas ya no sólo buscan que el conocimiento básico sea brindado por la universidad, sino también su aplicación a la producción (Vence Deza, 1995; Salomon, 1974). Especialmente en las áreas tecnológicas y de ciencias exactas y naturales (en menor medida), los investigadores asumen esta nueva responsabilidad de la universidad tomando como ejemplo el caso de Estados Unidos. Como en este país se encuentran las universidades más prestigiosas se acepta la supuesta necesidad de adoptar este modelo donde la interacción con las empresas y el gobierno representa un círculo (o triángulo) virtuoso. En muchos casos se considera que esto se cumple cuando los grupos de las universidades locales atienden demandas y ello sirve para financiar materiales y equipamiento.

Sin embargo, la consecuencia que se hizo evidente de este proceso - justificado muchas veces con el discurso de la pertinencia social de la ciencia- es que los grupos universitarios se abocan a la atención de demandas inmediatas y particulares, dejando sin respuesta gran cantidad de demandas sociales críticas (Riquelme, 1997 y 2003). Desde las ciencias sociales y humanas los integrantes de grupos I+E reconocen la dificultad para dar soluciones definitivas a las problemáticas de los sectores con que trabajan. Por su parte, los equipos I+E pero de las ciencias exactas, naturales y campos tecnológicos, quienes mayoritariamente trabajan en problemáticas de producción (sean soluciones rutinarias o de desarrollo), declaran tener algo más de éxito si bien sus relaciones con esos sectores no son fáciles y alteran su actividades cotidianas.

Pero no sólo las actividades de investigación se orientan hacia el mercado. También se tornan palpables las ideas de Bernstein (1990) quien postula que las pedagogías orientadas al mercado trasladan el poder del control simbólico del Estado a los agentes económicos. Muchos de los entrevistados tomaron como algo esencial la inclusión en la currícula de las prácticas profesionales, en tanto supuestamente es lo que permite evaluar "la competencia del alumno para afrontar problemas reales". A su vez, y especialmente en los campos de ciencias exactas y naturales y tecnológicas, se inculca en los alumnos la necesidad de ser "innovadores" o "tener espíritu innovador" a fin de que al graduarse puedan crear sus propias empresas. Es evidente también aquí el fuerte influjo de las políticas científicas de tinte neoschumpeteriano o evolucionsita.

De más está decir que las lógicas de producción de conocimiento se ven sumamente alteradas y adquieren un vocabulario propio de la economía. La competencia entre grupos se hace algo habitual y aparece como uno de los factores explicativos del incremento de la especialización (Becher, 2001). Así, se abren líneas de trabajo a partir de que su novedad la transforma en una "temática más competitiva", tanto para las posibilidades de conseguir recursos, como para publicar y ejecutar transferencias o ventas.

Muchos autores han señalado también que esta etapa se encuentra signada no sólo por la incorporación de cánones mercantiles sino también por la escasez de recursos, la elección de estrategias de 
investigación comienza a ser influida a través de líneas o necesidades de financiamiento (Coraggio, 2001 y 2003; Gentili, 1998; Krotsch, 2001; Llomovatte, 2006; Mollis, 2001 y 2003; Riquelme, 2003). Esta es una situación definitivamente generalizada y naturalizada en la universidad actual, donde cada uno "tiene su tema definido, sabe hacerlo, lo que le gusta lo que lo atrae, pero, después, al buscar recursos es uno contra el mundo y hay que tratar de enfocar lo que uno sabe donde en ese momento hay recursos". Incluso, algunos entrevistados no llegaron a reconocer a la escasez de financiamiento como una limitante para la investigación, en tanto esto "puede ser subsanado con mayor o menor dificultad a través de la búsqueda de fondos propios". Este tipo de situación resulta más familiar en las universidades de las provincias y, especialmente, en la UNaM.

A su vez, tan importantes comienzan a ser las actividades ligadas al proceso económico que hoy encontramos cargos y jerarquías dentro de los grupos con relación directa con el mercado (Becher, 2001; Hevly, 1992). Se encuentran entrevistados que se auto-definieron como "el nexo con las empresas en cualquiera de los temas" o como "investigador-gerente" de un grupo. Estas nuevas prácticas se traducen en las funciones generales de la universidad que menciona Gibbons (1998): formación de profesionales que resuelvan problemas técnicos; acreditación conocimientos; creación de grupos mixtos de expertos, y donde principalmente los grupos se dedican a "la formación de gente dirigida a temáticas, lo cual es muy bien visto y necesitada por lo local'.

Las nuevas funciones nacen en su mayoría en la década del noventa cuando se imponen el discurso y las políticas de "vinculación", la cual cobra importancia por encima de las tradicionales funciones de extensión y transferencia (Riquelme y Langer, 2008; Llomovatte, 2006). En la actualidad, donde más desarrollada se encuentran este tipo de actividades es en las universidades más pequeñas y en facultades de áreas tecnológicas y de ciencias económicas. Allí los entrevistados valoraron en gran medida la realización de "talleres de vinculación tecnológica con el resto de las áreas de la universidad vinculados al sector empresarial", aunque en general resaltaron su carácter informal o voluntario.

La consecuencia de este tipo de políticas es la continua transposición de las categorías extensión, transferencia y vinculación, imponiéndose una lógica de brindar servicios (en general rutinarios) como forma de responsabilidad social (de Sousa Santos, 2005; Riquelme, 2008b). Es habitual que en el discurso de los universitarios se identifique a la relación con el medio o la sociedad con el brindar algún servicio particular.

La nueva lógica con que se piensan las funciones universitarias se naturaliza y se transforma en valores implícita o explícitamente respetados por lo que podría llamarse el mainstream de cada facultad o universidad. Pareciera como si algunas ideas recientes, tales como la conectividad y eficiencia en la transferencia de conocimientos especialmente al contexto local (Gibbons, 1997 y 1998), hubiesen existido en la institución de por vida. Así hubo entrevistados en las universidades de mayor escala (UBA y UNMdP) que se sentían aventajados por las instituciones más nuevas del conurbano bonaerense en tanto que han tenido la flexibilidad para trabajar en la resolución de problemas puntuales de su entorno local.

Este tipo de discurso potenció el movimiento hacia la especialización y tecnificación de las disciplinas científicas (Becher, 2001; Lefevre, 2005). Esto lo demuestra la intensificación de la creación de maestrías en todas las universidades, así como la generación de tecnicaturas de grado universitario ligado a demandas puntuales de sectores económicos (la tecnicatura en industria de la madera de la Facultad de Ciencias Forestales de la UNaM es un ejemplo de ello).

No obstante, desde el discurso de los entrevistados también puede percibirse cierto grado de desconcierto o incluso indignación por algunos de estos avances. Así como la gran mayoría acepta en pos de la legitimidad perdida la justificación de su labor a partir de la utilidad directa que le proporciona a un tercero, resulta más difícil la aceptación de que este tipo de labores sea medida a través de evaluaciones externas (Gibbons, 1998). Pero las críticas existen mayoritariamente en la UBA y en menor medida en la UNMdP, en otros casos ya existe el discurso respecto a la "aceptación de las 
reglas del juego" en tanto "resulta natural que para recibir recursos haya que demostrar productividad".

En definitiva, se arraiga la utilización de términos del sector privado dentro de la lógica de funcionamiento de la universidad pública. Es una preocupación habitual en los investigadores (especialmente los I+E) la medición de "impactos" no sólo en términos de conocimiento, sino también en términos económicos (reducción de costos o ampliación de ganancias).

Desde una visión de conjunto, las primeras reformas de mercado (80-90) parecieran haber sido más eficientes en cuanto a la instalación y naturalización de un discurso mercantilizador o regido por parámetros de utilidad social, que en la concreción de este tipo de actividades en forma efectiva. Las políticas con esta orientación propendieron a la realización de nuevas prácticas y de transformación de procesos de trabajo, pero hasta fines de la década del noventa no lograron tener la coherencia necesaria tanto a nivel interno de las instituciones científicas como con los demás sectores sociales. Pareciera ser que este es el nuevo paso que busca darse con la diagramación de políticas a partir del nuevo siglo.

\subsubsection{Influencia de las lógicas de competitividad o pertinencia social del nuevo siglo en la universidad actual}

Nos adentramos por último en el estudio de los cambios acaecidos en las lógicas de producción de conocimiento dentro de la universidad durante los últimos años. Una de sus principales complejidades radica en que, desde el campo de la política, se dice haber cambiado la orientación y la importancia otorgada a la ciencia en el país. Sin duda que los años posteriores a la crisis de 2001 vinieron con mayores recursos para los grupos de investigación, pero como hemos visto esto no implicó un cambio en el ahogo presupuestario que sufre la universidad y tampoco una marcada transformación en las ideas que marcan el rumbo de las políticas científicas y universitarias hacia la instauración de lógicas privadas o mercantiles.

En forma mucho más aceptada que en el período anterior, las demandas juegan un rol activo dentro del sistema y la actividad científica en Argentina. Resulta claro que en todas las universidades y en distintos campos de conocimiento se apela (al menos retóricamente) a la observación de las demandas para la elección de temáticas de investigación (Langer, 2008). En la UNaM esto fue una evidencia en la mayoría de las entrevistas realizadas, donde los investigadores se esforzaron por mostrar a qué sector de la industria local (facultades tecnológicas y de ciencias exactas, naturales y ciencias económicas) o de la sociedad (ciencias sociales y humanas) favorecían sus actividades. Sin embargo, también en la UNMdP y la UBA varios de los investigadores-docentes adoptaban el discurso sobre la preocupación por la "atención a demandas sociales en la elección de los proyectos de trabajo".

La importancia que ha tomado la atención a demandas ejemplifica el tránsito que la universidad argentina (y el sistema científico general) ha iniciado hacia la creación de una nueva lógica de producción de conocimiento pluriuniversitaria o de traspaso del modo 1 al modo 2 (De Sousa Santos, 2005 Gibbons, 1998). Resultó habitual - especialmente en ámbitos de las ciencias sociales y humanasla interacción del investigador con su objeto de estudio para la definición de líneas de trabajo. La idea principal pasa por "escuchar de boca de los propios protagonistas sociales cuáles son las demandas que ellos tienen y cómo creen que nosotros podemos contribuir a solucionar esas demandas". También entre quienes se desempeñan en facultades de ciencias económicas y ciencias médicas se reconocía la continua interacción con sectores empresarios para "los que está dirigido" su trabajo.

Sin embargo, la situación no resulta sencilla e incluso se torna en regresiva en términos de desarrollo económico y social ya que hay una marcada imposibilidad de gran cantidad de sectores para revelar sus demandas, lo cual se torna en un consecuente dominio de quienes poseen mayores recursos económicos (Riquelme, 2003 y 2008b). Los entrevistados dieron cuenta del problema, especialmente quienes trabajan en áreas humanísticas o sociales y en algunos casos ciencias de la salud, mientras que en áreas de exactas e ingenierías el grado de consciencia es menor. Los problemas más mencionados fueron la imposibilidad de acceso a la universidad de organizaciones de menores recursos monetarios 
y de organización, o de culturas más lejanas a la institución, así como la necesidad salir a buscar las demandas ya que estas no llegan en espontánea a la universidad.

También regresiva resulta la situación de que la mayoría de las demandas que dijeron atender los investigadores son de carácter adaptativo y revisten poca originalidad científica (Iñigo Carrera, 2007). Los grados de reconocimiento de los universitarios de esta problemáticas resultaron sumamente divergentes. En la UNaM hubo muy pocas menciones al tema, pero en la UBA y la UNMdP muchos aceptaron que la mayor parte de la atención a empresas se reduce a "provisión de servicios técnicos, asesoría o actividades de consultoría", siendo muy pocos los desarrollos tecnológicos (incluso los que significan adaptaciones y no cuestiones originales). Esto se potencia en las facultades de ciencias sociales y humanas donde la atención a demandas parte en su mayoría por resolver problemas básicos existentes en sectores sociales marginales o en situaciones límites de pobreza.

En este marco comienzan a ser más habituales los contactos interdisciplinares e incluso con organismos e instituciones externas a la universidad, en general, con el objeto de resolver un problema concreto. No obstante, mucho dista esta situación de representar lo que varios autores de países desarrollados entienden como potencia de la interdisciplina: entrenamiento creativo para la resolución de problemas y como forma transformadora de pensar los problemas del conocimiento (Pohl, 2005; Boix Mansilla y Gardner, 2004; Rhoten, 2003 y 2004). Más bien resultan en formas (creativas o no) para resolver problemas a bajo costo de empresas o solucionar situaciones extremas no cubiertas por las políticas sociales estatales (Riquelme, 2003).

Lo que predomina, entonces, en la articulación entre diversos grupos universitarios es el intercambio de información más que la creación de nuevo conocimiento (Rhoten, 2004). Entre quienes realizan actividades en redes, se reconoció la formación de grupos a fin de cumplimentar proyectos concretos y donde la mayor parte de intercambio se da entre disciplinas afines o entre especialistas diversos de una misma disciplina. A pesar de ello, pueden encontrarse islas de desarrollo interdisciplinar que representa avances interesantes en las formas de producción de conocimiento científico. Un ejemplo son las recientes actividades en el área de neurociencias que se desarrollan en grupos de la UBA.

Pero no parecería haber una tendencia a que estas islas de conocimiento dejen de serlo, por el contrario, estarían acertadas aquellas tesis que proponen que los últimos años han sido marcados por políticas con un fuerte grado de economicismo que actúan en detrimento de las lógicas académicas y de grupos sociales de menor poder (Dagnino, 2007). De los discursos de los entrevistados se obtiene una evidencia paradojal, en tanto que las políticas científicas enfatizan la necesidad de relación interdisciplinar, crean a la vez un clima de competencia muy grande que dificulta la relación entre grupos (especialmente dentro del país).

El efecto de las últimas políticas científicas parecen estar en sintonía con las del mundo desarrollado, donde los incrementos de fondos se centralizan y destinan a temas cada vez más específicos y con potenciales aplicaciones (Hevly, 1992). A su vez, también parecería acentuarse la situación de que quien ingresa en la lógica propuesta por las políticas logra acumular cada vez más prestigio y recursos (Becher, 2001). Muchos entrevistados aceptaron la existencia de una lógica donde se actúa en función de "hacer rodar una gran bola de nieve, que le permite tener cada vez más al que más tiene". Así se habla de papers que no son producciones reales sino "refritos" o de proyectos de investigación ganadores de subsidios que, en realidad, son "cambios de escala de un conocimiento ya existente", es decir transferencias. Incluso esto último, escapa a la lógica interna del sector y transforma a la política científica en una subsidiadora del sector privado (Riquelme, 2008b).

En definitiva podríamos entender que estamos al inicio de una disputa que ya tiene algo de historia en el primer mundo donde se propone que las universidades se organicen institucionalmente a la manera de los institutos de tecnología (ver Lok, 2008; Galison, 1992). Pero los pretendidos cambios generan profundas dislocaciones entre las actividades que se les pide desarrollen los investigadores y el tipo de organización estructural que poseen sus instituciones (Bernstein, 1990; Rhoten, 2004). En todas las universidades los investigadores hablaron de la ineficiencia de las políticas de transferencia de sus 
instituciones, las que se tornan en impedimentos para su accionar en este terreno. También en este sentido se habló de la poca organicidad y planificación con que se desarrollan las actividades de extensión/transferencia, en tanto dependen principalmente de la acción individual del investigador.

A partir del desarrollo de la tesis comprendemos que la serie de complicaciones que los entrevistados fueron mencionando para la concreción de actividades de transferencia tecnológica es una forma en que se expresa la especificidad de la estructura económica del país donde, a menos que se efectúe algún tipo de planificación sectorial (casi inexistente en la actualidad), pensar una aplicación directa para cada proyecto de investigación universitario resulta ficticio. De esta forma, aún sin que medie esta reflexión, es posible observar fenómenos como el de los "conocimientos aplicables no aplicados" (Kreimer y Thomas, 2005) donde se inician proyectos de investigación con miras a la realización de un transferencia, pero luego no se tiene una contraparte donde desarrollar la aplicación. Lo extraño de la cuestión es que, por más que esto suceda, muchos investigadores siguen persistiendo en la misma lógica de trabajo, lo cual se reveló especialmente en la UNaM (Riquelme y Langer, 2008).

Encontramos en los últimos años movimientos/transformaciones que, al observarlas con alguna detención, aparecen como confusas o contradictorias. Bajo un discurso anti-mercado se desarrollan políticas pro-mercado. A través de dichos que dan importancia a la ciencia se desfinancia la actividad científica universitaria. A la retórica de la relevancia social del conocimiento se le responde con pocos canales de acceso a la sociedad. A las presiones por la aplicación se le opone la no planificación sectorial y el desentendimiento estatal para lograrlo. Al ideario universitario se lo ataca con nociones creadas fuera de la institución que buscan afectar su legitimidad y hegemonía en la creación de conocimiento.

Dado este contexto, no es extraña la confusión reinante dentro de los grupos universitarios respecto a las nociones sobre las funciones o rol social de su institución (Riquelme, 2008a). En el caso particular de los grupos seleccionados, por ejemplo, se observan distintas concepciones respecto a lo que es la investigación, si bien especialmente tiende a fundirse con su aplicación (extensión). Esto se encuentra en línea con lo que hace tiempo se ha propuesto respecto a que especialmente a partir de la década del setenta la investigación es investigación y su aplicación (Salomon, 1974; Elzinga, 1987). Desde las ideas de los investigadores-docentes esto se revela en su preocupación por el reconocimiento social de su trabajo, lo cual, entienden, se logra a partir de transferir y difundir productos de su actividad. Este tipo de discurso promueve, además, la realización de investigación básica pero en función de alguna potencial aplicación; lo cual en muchos casos se define según su interés económico. Se ha propuesto, incluso, la idea de "hacer investigación básica con fuerte énfasis en los grupos que tienen interés económico. No sería cambiar la línea, sino tratar de restringirla a esos grupos".

La universidad se encuentra ante una encrucijada donde se propone un torbellino de ideas y posibilidades generalmente contrapuestas y donde las prácticas y discursos de sus actores reflejan fielmente estas contradicciones. Será cuestión de indagar dentro de esas contradicciones para llegar a una discusión donde la razón prime nuevamente dentro de su antigua casa.

\subsection{Transformación de las ciencias en Argentina y su rol en el desarrollo económico y social: en busca de nuevos interrogantes}

En esta tesis centramos el análisis de la universidad como una de las principales instituciones productoras de conocimiento en el país, con lo cual ha quedado en cierta forma relegado su rol docente. Ello no implica el desconocimiento de esta importante misión de la institución, sino simplemente que nuestro foco de interés es la ciencia y, en particular, la ciencia en argentina y su relación con las potencialidades de desarrollo del país.

Dentro de este marco, lo que ha surgido como evidencia del estudio realizado es que la importante contraposición de ideas y teorías respecto al desarrollo de los sistemas científicos y universitarios se ven correspondidas con la multiplicidad de prácticas/procesos que existen dentro de las instituciones. Dependiendo especialmente del campo del conocimiento (aunque también a veces de la ubicación 
geográfica), encontramos diversas posiciones respecto a las funciones que debería cumplir la universidad pública, lo cual, a su vez, se manifiesta en una gran diferenciación y fragmentación de sus actores o investigadores-docentes.

Nos queda claro que el desarrollo de la universidad (y dada su relevancia, en la ciencia en Argentina) no resulta de ninguna manera monolítico, sino que ocurre en un contexto de disputas y tensiones permanentes. Creemos que el entorno general de estos conflictos que se nos aparecen como polítcoideológicos, toma sus características de la estructura económica y del particular lugar en la división internacional del trabajo que ocupa el país. La tensión principal se encuentra entre dos modelos muy generales ligados, por un lado, a la dependencia de las demandas y, por otro, a la necesidad de un saber completamente autónomo y auto-reflexivo que marche tras el saber absoluto o universal. A su vez, el primer modelo tiene dentro una fuerte escisión, donde encontramos aquellos que se orientan a responder a requisitos puramente económicos o de mercado y quienes defienden la atención directa de demandas realizadas por sectores populares. La cuestión (al menos en Argentina) llega a plantearse como una disputa ideológica sobre el deber ser de la institución universitaria, entre quienes pretenden conservar indemnes los valores de la ciencia moderna creados hace dos siglos y aquellos que dan cuenta de manera acrítica de las presiones que ejerce el medio social. Esto afecta directamente el rol social de la ciencia en tanto se pierde la valoración por lo que esta es: una institución con la potencia capaz de transformar (trascender) las fronteras de lo existente. Por el contrario, la disputa ideológica la desvirtúa y se la comienza a valorar a partir de su capacidad para ampliar o mejorar (reproducir/ampliar) las estructuras sociales vigentes.

La forma en que ha mutado la esfera de la ciencia la ha revestido de un fuerte carácter tecnológico, lo que influye sobre qué es lo que es y hace la ciencia. Se ha perdido la noción de cuál es el verdadero rol de la ciencia pura, ya que esta se observa siempre a través de sus resultados en la esfera de la producción (en forma indirecta) y donde la lógica de la explicación científica es directamente la de la producción. Es decir, en apariencia, la explicación científica de un fenómeno sólo es posible a partir de su derivación en el proceso que produce o podría producir. El principal problema a que nos enfrenta esta última tendencia es que, dado que especialmente en los países subdesarrollados, la creación de conocimiento original es responsabilidad de entidades estatales (más que nada de la universidad), si además se les exige a estos organismos su participación en la aplicación, necesariamente la creación de conocimiento tenderá a desaparecer. Se condena así al sistema económico nacional a reproducir conocimientos creados fuera y, por tanto, a incrementar su grado de dependencia externa. Un sistema científico con estas características, en lugar de fomentar la autonomía nacional, crea su contrario.

Este proceso es afectado por la transformación en las formas de producción de las sociedades y, por tanto, por los cambios en la estructura económico-social. Para dar cuenta de ello debería evaluarse la posibilidad de recuperar un campo que relacione las condiciones estructurales con el de las ideas y prácticas en la ciencia; ese campo, entendemos, es el de la economía política de la ciencia.

¿Qué implica este campo a la luz del trabajo realizado en la tesis? Resulta limitado lo que aún se puede decir, pero se ha hecho evidente que el cambio en las formas de producción de nuestra sociedad no es un hecho aislado ni fortuito, sino que está relacionado con el desarrollo histórico del sistema capitalista. El estudio de este desarrollo tendrá como resultado la comprensión de la relación actual entre avance técnico y producción, así como las diferencias que existen en esta relación en cada región o nación.

Sin embargo, algunos estudios, al tomar como un hecho extrínseco la forma en que se integran cambio tecnológico y producción, concluyen que quien lidera estos cambios es un empresario individual, cuya mayor virtud es el ingenio y creatividad que utiliza para mantener siempre elevadas las ganancias de su empresa, generando innovaciones que le permitan tener un plus de ventaja por sobre sus competidores. Como consecuencia de este proceso de innovación continua, se entiende que se van destruyendo las viejas formas de producción y creando otras nuevas. Se crea así un supuesto círculo virtuoso donde sólo en el principio de la innovación se obtienen grandes márgenes de utilidad, que luego tienden a bajar a medida que aparecen adaptaciones e ingresan nuevas empresas. La estructura 
de mercado se torna cada vez más competitiva y su expansión dependerá de la demanda existente por el producto en cuestión. La igualación de las tasas de ganancia, a su vez, incentivará a otro empresario emprendedor a generar una nueva innovación para otra vez obtener una mayor parte del mercado y de ganancias. De esta forma la sociedad avanza en un clima de competencia e incremento de las posibilidades de consumo. El virtuosismo sólo podría romperse ante la inexistencia de empresarios con voluntad emprendedora y/o de incapacidad empresaria para adaptar o imitar las nuevas tecnologías.

Por tanto, desde esta visión, quien no adopte las nuevas técnicas no sólo no tendrá ganancias extraordinarias, sino que ni siquiera podrá permanecer en el mercado. Aquí comienzan a jugar un papel muy importante las instituciones científicas en tanto herramientas capaces de potenciar al emprendedor individual en el proceso de competencia global. Estas son las ideas que, preponderantemente, han adoptado los hacedores de política científica en nuestro país en lo que va del nuevo siglo y que muchos de los investigadores del país aceptan explícita o implícitamente (a partir de su acción o inacción).

Siguiendo esta lógica pareciera ser que el proceso de cambio tecnológico y el consecuente progreso económico depende exclusivamente de la voluntad individual del empresario, quien en su afán de acumular (o al menos mantenerse en el mercado) decide involucrarse en una carrera continua de investigación y desarrollo. Su progreso será a la vez el progreso de todos (o al menos todos de los que accedan al "derrame" de esta empresa). Todo pareciera depender de voluntarismos políticos o individuales. Un Estado que invierta en ciencia, una universidad que genere conocimiento, un empresariado que asuma riesgos y un marco de contención que enlace de la mejor manera posible a estos tres actores. Difícil, pero no imposible. Las posibilidades parecieran estar para cualquiera que asuma con seriedad este problema. Esta es la postura que vimos reflejada al realizar algunas consideraciones sobre la política científica y universitaria en Argentina, así como en las ideas que tienen los propios investigadores y docentes de la universidad.

Se ha hecho evidente que la política científica y universitaria de los últimos años ha buscado transformar las funciones de la universidad y la propia práctica de sus grupos con un norte fijo en los aportes inmediatos que podrían hacerse a la competitividad del individuo innovador o, incluso, a la calidad de vida de los individuos o grupos de carácter marginal. Puede reconocerse como resultado de nuestra indagación que este tipo de políticas ha sido en gran medida aceptada por quienes conforman las instituciones, si bien permanecen las críticas o problemáticas debido a la aún muy baja posibilidad de financiamiento de las actividades científicas y académicas.

Bajo el discurso de la directa utilidad que debe tener la producción de conocimiento, la mayoría de los grupos de la universidad actual han transformado sus procesos de trabajo en relación a las existentes en otros momentos la historia. Si bien permanecen disputas internas, estas parecerían reducirse en su mayoría al debate sobre los sectores que deberían ser asistidos por la universidad pública. De una u otra forma, parece haberse impuesto la idea de que la universidad tiene su razón de existir (o al menos se legitima) en tanto sea positiva su ecuación costo (lo que el Estado gasta en su manutención)beneficio (lo que diversos sectores o individuos de la sociedad reciben en forma directa de ella). Como en cualquier estudio económico, dentro de los beneficios no cuentan los montos abstractos, tales como sus aportes a la creación de una cultura nacional y autónoma o la transformación/trascendencia de las consciencias en el estudio de las problemáticas naturales y sociales del país, la región y/o el mundo.

Entendemos que la planificación de políticas que relacionen el desarrollo económico y social con el área de educación superior, ciencia y tecnología debe considerar cuestiones mayormente estructurales de ambas esferas. Una línea para continuar mi trabajo en este sentido sería, por una parte, la evaluación de nichos de desarrollo económico con posibilidades de competencia a nivel internacional $y$, por otra, el estudio de las capacidades científicas existentes en universidades y otros institutos de ciencias del país. Estas dos dimensiones resultarían insumos claves para una eventual política de programación del desarrollo que tenga como fin la creación de sub-sistemas de producción compuestos por empresas no reproductoras de bienes basadas en conocimiento ajeno, sino creadoras 
de mercancías con uso de conocimiento realmente original. Este tipo de reflexiones fueron permitidas por el trabajo de maestría y abren el camino a nuevas problemáticas para una tesis doctoral.

La discusión acerca de las nociones y discursos sobre la ciencia en relación a las prácticas concretas de los investigadores-docentes universitarios también contribuyó en la búsqueda de nuevos interrogantes. En este sentido resulta necesario profundizar el análisis de las prácticas científicas en su carácter de procesos de trabajo. Si sostenemos el carácter de la ciencia como una rama de la producción, entonces los científicos estarían limitados en su accionar en tanto participantes de un proceso material de producción. Por tanto habría que comprender la forma en que esto se ve reflejado en la actividad habitual del hombre de ciencia y su capacidad de contribución genuina a la producción de conocimiento original en el país.

En cuanto a los contenidos de las prácticas de los universitarios se identificaron algunas contradicciones cuya resolución podría hacernos avanzar en nuestro grado de entendimiento sobre la relación entre ciencia, tecnología y desarrollo: i) ¿Es posible romper estructuras disciplinares y, a la vez, formar expertos en problemas puntuales?; ii) ¿En qué se diferencian la extensión, la transferencia y la vinculación? ¿La investigación es un proceso distinto al de su aplicación?; iii) ¿Cómo puede solucionarse un conflicto netamente ideológico que proponen dos deber ser completamente distintos para las instituciones científicas (servir a intereses económicos dominantes o a sectores sociales marginados)?; iv) ¿Es un criterio posible el de autonomía derivada de una planificación pública de la innovación?; v) ¿Cómo afrontar las disparidades de desarrollo e ideas entre instituciones y campos de conocimiento?

A su vez, estos discursos han presentado incoherencias internas que nos provocan nuevas preguntas: i) ¿Cómo compatibilizar la difusión del conocimiento con su apropiación mediante patentes?; ii) ¿Qué diferencias existen entre transformar universidades en laboratorios I+D privados y subsidios/exenciones directas a empresas?; iii) ¿Se logra diferenciar entre la apropiación de los resultados del conocimiento y del propio conocimiento?; iv) ¿Cómo se piensa en planificar un sistema de I+D innovador en el marco de una estructura económico-social no innovadora o dependiente?

Todos estos últimos interrogantes deberían ser integrados a la pregunta macro o estructural respecto a cómo avanzar en la construcción de un verdadero sistema de educación superior, ciencia y tecnología que actúe, a su vez, como dinamizador en una estrategia de desarrollo nacional y autónomo.

\section{Bibliografía}

Albornoz, M. (1997) «La política científica y tecnológica en América Latina frente al desafío del pensamiento único», en Revista Redes, Vol. IV, $N^{\circ}$ 10, octubre, Instituto de Estudios Sociales de la Ciencia y la Tecnología, Universidad Nacional de Quilmes.

Albornoz, M. (2002) «Situación de la ciencia y la tecnología en las Américas», documento de trabajo $N^{\circ} 3$, Centro Redes [en línea] http://www.centroredes.org.ar/

Banco Mundial (1999); Informe sobre el desarrollo mundial 1998/1999. El conocimiento al servicio del desarrollo, Madrid, Ediciones Mundi-Prensa.

Banco Mundial (2000) Higher Education in Developing Countries. Peril and Promise, Washington, World Bank.

Becher, T. (2001); Tribus y territorios académicos. La indagación intelectual y las culturas de las disciplinas, Barcelona, Editorial Gedisa.

Bernstein, B. (1990a); "Social class and pedagogic practice" en The Structuring of Pedagogic Discourse, Volume IV, Class, codes and control, London, Routledge.

Bernstein, B. (1990b); "Education, symbolic control and social practices" en The Structuring of Pedagogic Discourse, Volume IV, Class, codes and control, London, Routledge.

Bertoni, M. L. y D. Cano (1990) «La educación superior argentina en los últimos veinte años: tendencias y políticas», en Propuesta Educativa, № 2, FLACSO, Buenos Aires. 
Boix Mansilla, Verónica y Gardner, Howard (2004); “Assesing Interdisciplinary Work at the Frontier. An empirical exploration of "symptoms of quality", Interdisciplines. En línea: http://www.interdisciplines.org/interdisciplinarity/papers/6

Bourdieu, P. (2003) Los usos sociales de la ciencia. Por una sociología clínica del campo científico, Buenos Aires, Nueva Visión.

Buchbinder, P. (2005) Historia de las Universidades argentinas, Buenos Aires, Editorial Sudamericana.

Bush, V. (1999) «Ciencia, la frontera sin fin», en Revista Redes, № 14, noviembre, Buenos Aires, pp. 89-137.

Campa, R. (1989); La Universidad de Bolonia y el debate de la razón, Buenos Aires, Grupo Editor Latinoamericano.

Carnoy, M. (1996); "Multinationals in a Changing World Economy: Whither the Nation-State?" en Carnoy, Castells, Cohen y Cardoso, The New Global Economy in the Information Age, Pennsylvania, The Pennsylvania State University Press, p. 45-96.

Carnoy, M. (2000); Globalization and Educational Restructuring, Internacional Institute of Educational Planning, Paris.

Castells, M. (1996); "The Informational Economy and the New International Division of Labor" en Carnoy, Castells, Cohen y Cardoso, The New Global Economy in the Information Age, Pennsylvania, The Pennsylvania State University Press, p. 15-44.

Cavallo, D. y J. Cottani (1997) «Argentina Convertibility Plan and the IMF», en The American Economic Review, Vol. 87, Issue 2, Papers and Proceedings of the Hundred and Fourth Anual Meeting of the American Economic Association, pp. 17-22.

Chudnovsky, D.; López, A. (1995); Política tecnológica en la Argentina: ¿Hay algo más que laissez faire?, Buenos Aires, CENIT.

Cereijido, M. y L. Reinking (2003) La ignorancia debida, Buenos Aires, El Zorzal.

Coraggio, J. L. (2003) «La crisis y las universidades públicas en Argentina», en Mollis, M. (comp.) Las universidades en América Latina: ¿Reformadas o alteradas? La cosmética del poder financiero, Buenos Aires, CLACSO.

Coraggio, J. L. y A. Vispo (2001) Contribución al estudio del sistema universitario argentino, Buenos Aires, Miño y Dávila editores - CIN.

Dagnino, R. (2007) «As trajetórias dos estudos sobre ciência, tecnologia e sociedade e da política científica e tecnológica na ibero-américa», trabajo elaborado en el Programa Cátedra Ibero-Americana Unicamp y Universidades Españolas, en Primer Congreso Argentino de Estudios Sociales de la Ciencia y la Tecnología [CD ROM], Universidad Nacional de Quilmes, 5 y 6 de julio.

Dotti, J. (1993); Dialéctica y derecho. El proyecto ético-político hegeliano, Buenos Aires, Editorial Hachette.

Dotti, J. E. (2001) «Filosofía política y universidad: una aproximación», en Naishtat, F. (comp) y otros, Filosofías de la Universidad y conflicto de racionalidades, Buenos Aires, Ediciones Colihue, pp. 33-42.

Elzinga, A. (1987); "Internal and external regulatives in research and higher education systems" En Premfors, R. (comp.) Disciplinary Perspectives on Higher Education and Research, $\mathrm{N}^{\circ} 37$, Estocolmo, University of Stockholm GSHR.

Estebanez, M. E. (2003) «Impacto social de la ciencia y la tecnología: estrategia para su análisis», en RICYT, El estado de la ciencia. Principales indicadores de ciencia y tecnología iberoamericanos/interamericanos 2002, Buenos Aires, RICYT, pp. 83-92.

Etzkowitz, H. y Leydesdorff (2001) «The Transformation of University-Industry-Government Relations» Electronic Journal of Sociology [en línea]. 
Etzkowitz, H. (2002) The Triple Helix of University-Industry-Government. Implications for Policy and Evaluation, Working Paper 2002-11, Estocolmo, Sister.

Fernández Polcuch, E. (2001) «La medición del impacto social de la ciencia y la tecnología», en Albornoz, M. (comp.), Temas actuales de indicadores de ciencia y tecnología en América Latina y El Caribe, Buenos Aires, Ricyt, pp. 225-246.

Fichte, J. (1959); "Plan razonado para erigir en Berlín un establecimiento de enseñanza superior" en Instituto de Filosofía de la Facultad de Humanidades y Ciencias de la Universidad de Montevideo, La idea de la universidad en Alemania, Buenos Aires, Editorial Sudamericana, pp. 15-95.

Frondizi, R. (1971); La universidad en un mundo de tensiones. Misión de la universidad en América Latina, Buenos Aires, Editorial Paidós.

Galison, B. (1992); “The Many Faces of Big Science" en Galison y Hevly (ed.) Big Science. The Growth of Large-Scale Research, Stanford, California, Stanford University Press, pp. 1-17.

Gentili, P. (1998) A falsificação do consenso. Simulacro e imposição na reforma educacional do neoliberalismo, Petrópolis, Vozes.

Gibbons, M. (1994) The New Production of Knowledge: Science and Research in Contemporary Societies, London, Sage.

Gibbons, M. (1997) La nueva producción del conocimiento. La dinámica de la ciencia y la investigación en las sociedades contemporáneas, Barcelona, Ediciones Pomares-Corredor.

Gibbons, M. (1998); Higher Education Relevance in the 21st Century, Banco Mundial.

Gómez Campo, V. y E. Tenti Fanfani (1989) Universidad y profesiones. Crisis y alternativas, Buenos Aires, Miño y Dávila editores, Buenos Aires.

Habermas, J. (1997); "The Idea of the University: Learning Processes", s/d.

Hevly, B. (1992); "Reflections on Big Science and Big History" en Galison y Hevly (ed.) Big Science. The Growth of Large-Scale Research, Stanford, California, Stanford University Press, pp. 355-366.

Herrera, A. (1974) Ciencia y política en América Latina, México, Siglo XXI.

Herrera, A. (1995) «Los determinantes sociales de la política científica en América Latina. Política científica explícita y política científica implícita», en Revista Redes, $\mathrm{N}^{\circ}$ 5, Universidad Nacional de Quilmes.

Hyppolite, J. (1981); Introducción a la filosofía de la historia de Hegel, Montevideo, Ediciones Caldén.

Humboldt, W. (1959); "Sobre la organización interna y externa de los establecimientos científicos superiores en Berlín" en Instituto de Filosofía de la Facultad de Humanidades y Ciencias de la Universidad de Montevideo, La idea de la universidad en Alemania, Buenos Aires, Editorial Sudamericana, pp. 209-220.

Iñigo Carrera, J. (2007) La formación económica de la sociedad argentina, Vol. I Renta agraria, ganancia industrial y deuda externa. 1882-2004, Buenos Aires, Imago Mundi.

Jaspers, K. (1959); "La idea de universidad" en Instituto de Filosofía de la Facultad de Humanidades y Ciencias de la Universidad de Montevideo, La idea de la universidad en Alemania, Buenos Aires, Editorial Sudamericana, pp. 391-524.

Kreimer, P. (2006) «¿Una nueva dependencia? La investigación científica en América Latina, integración subordinada y división internacional del trabajo», en Revista Nómadas, marzo, Bogotá.

Kreimer, P. y H. Thomas (2005) «What is CANA? Social Utility of Scientific and Technological Knowledge: challenges for Latin American Research Centres», en Meyer y Carton (eds.), Development through Knowledge? A New Look at the Global Knowledge-Based Economy and Society, Ginebra, IUED.

Krotsch, P. (2001) Educación superior y reformas comparadas, Prov. de Buenos Aires, Universidad Nacional de Quilmes. 
Langer, A. (2008); "El sistema científico y las universidades: revisión de teorías y enfoques en América Latina y Argentina" en Riquelme, Graciela (ed.) Las universidades frente a las demandas sociales y productivas. Capacidades de los grupos de docencia e investigación en la producción y circulación de conocimiento, Buenos Aires, Miño y Dávila editores.

Latour, B. (1993) Nunca hemos sido modernos, Madrid, Editorial Debate.

Lefevre, W. (2005); "Science as Labor" en Perspectives on Science, vol. 13, n 2, The Massachusetts Institute of Technology, p. 194-225.

Levín, Pablo (1996); Economía política del capital tecnológico, CENDES, Caracas.

Llomovatte, S. (2006) «Para una crítica del modelo de la triple hélice: Universidad, Empresa y Estado» en Llomovate, S. (dir.), La vinculación universidad-empresa: miradas críticas desde la universidad pública, Buenos Aires, Miño y Dávila editores.

Lok, C. (2008); "Harvard under Review", News Feature, Nature, Vol. 454, 7 august, Macmillan Publishers Limited.

Lukács, G. (1985); Historia y consciencia de clase I, Madrid, Editorial Sarpe.

Marx, K. (1986) El Capital, México, Fondo de Cultura Económica, México, tomo I.

Mollis, M. (2001) La universidad argentina en tránsito, Buenos Aires, Fondo de Cultura Económica.

Mollis, M. (2003); "Un breve diagnóstico de las universidades argentinas: identidades alteradas" en Mollis, M. (comp.) Las universidades en América Latina: ¿reformadas o alteradas? La cosmética del poder financiero, Buenos Aires, CLACSO, p. 203-215.

Monza, A. y G. Riquelme (1997) Metodología para el estudio de las demandas a la educación superior, Buenos Aires, CPRES, Región Metropolitana.

Naidorf, J. (2005); "La privatización del conocimiento público en universidades públicas", en Gentili y Levy Estudios sobre políticas de educación superior en América Latina, Buenos Aires, CLACSO.

Naishtat, F. y otros (2001) «La universidad hoy: crisis de esa buena idea», en Naishtat, F. (comp.) y otros, Filosofías de la Universidad y conflicto de racionalidades, Buenos Aires, Colihue, pp. 19-32.

Naishtat, F. y Aronson P. (comp.) (2008); “Genealogías de la universidad contemporánea. Sobre la Ilustración o pequeñas historias de grandes relatos", Buenos Aires, Biblos.

Oteiza, E. (1992) La política de investigación científica y tecnológica argentina. Historia y perspectivas, Buenos Aires, Centro Editor de América Latina.

Oteiza, E. (1996) «Dimensiones políticas de la política científica y tecnológica», en Albornoz (ed.) y otros, Ciencia y sociedad en América Latina, Universidad Nacional de Quilmes.

Pestre, D. (2005) Ciencia, dinero y política, Buenos Aires, Nueva Visión.

PICTR00013 (2003/2006); "Investigación, transferencia, extensión y vinculación: análisis de las concepciones en la política científica y universitaria de la Argentina”, Documento de trabajo $\mathrm{N}^{\circ} 6$, Langer, Ariel.

PICTR00013 (2003); "Relevamiento bibliográfico y documental", Documento de trabajo $\mathrm{N}^{\circ} 9$, Riquelme, Graciela C., Pacenza, María Inés y Langer, Ariel.

PICTR00013 (2007); "Relevamiento bibliográfico y documental (segunda parte)", Documento de trabajo $\mathrm{N}^{\circ} 30$, Riquelme, Graciela C. y Langer, Ariel.

Pohl, C. (2005) «Transdisciplinary Collaboration in Environmental Research», en Futures, 37 (11591178) [en línea] University of Liverpool, http://findarticles.com/p/articles/mi_hb4750/is_200512/ai_n17323976

Rhoten, Diana (2003); “A Multi-method análisis of the social and technical conditions for interdisciplinary collaboration", The Irbid Vigor Institute, San Francisco, CA. En línea: http://hybridvigor.org

Rhoten, Diana (2004); Interdisciplinary Research: Trend or Transition, s/d. 
Ricouer, P. (2000); "Perspectivas de la Universidad contemporánea para 1980" en Revista Pensamiento Universitario, s/d, pp. 81-91.

Riquelme, G. C. (2008a) "La lógica de construcción de un proyecto interuniversitario (en redes) sobre las capacidades de las universidades frente a las demandas sociales y productivas", en Riquelme, Graciela (ed.) Las universidades frente a las demandas sociales y productivas. Capacidades de los grupos de docencia e investigación en la producción y circulación de conocimiento, Buenos Aires, Miño y Dávila editores.

Riquelme, G.C. (2008b); “Acerca de la producción y circulación de conocimiento y de la sinergia pedagógica en las funciones de docencia, investigación, transferencia y extensión" en Riquelme, Graciela (ed.) Las universidades frente a las demandas sociales y productivas. Capacidades de los grupos de docencia e investigación en la producción y circulación de conocimiento, Buenos Aires, Miño y Dávila editores.

Riquelme, G.C., Herger, N.; Langer, A. (2005); "Educación y formación para el trabajo en Argentina. Continuidades, rupturas y desafíos en los últimos cincuenta años. Perspectiva para la relación educación y mercado de trabajo en el 2005". Working paper, en "Cuadernos de Educación, Economía y Trabajo” No 18, Programa Educación, Economía y Trabajo, Universidad de Buenos Aires.

Riquelme, G. C. (2003) Educación superior, demandas sociales y productivas y mercado de trabajo, Buenos Aires, Miño y Dávila editores.

Riquelme, G. C. (2004) «La educación superior entre los discursos de la sociedad del conocimiento, el desarrollo científico tecnológico y la deuda interna social: mitos, realidades y utopía». Elaborado para el panel Transformaciones en el mundo del trabajo, propuestas curriculares y estrategias de formación. IV Encuentro Nacional y I Latinoamericano «La universidad como objeto de investigación» [CD ROM], Universidad Nacional de Tucumán, San Miguel de Tucumán, octubre.

Riquelme, Graciela (2000); "La educación formal y no formal de los trabajadores: diferenciales para el área metropolitana, regiones y por ingresos"; Programa MECOVI-Argentina. INDEC-BID-BMCEPAL, Buenos Aires.

Sábato, J. y N. Botana (1968) «Ciencia y tecnología en el desarrollo de América Latina», en Revista de Integración, № 3, Buenos Aires.

Salomon, J. J. (1974) Ciencia y política, México, Siglo XXI.

Schorr, M. (2004); Industria y nación, Buenos Aires, Edhasa - IDAES.

Sousa Santos, B. de (2005); La Universidad en el siglo XXI. Para una reforma democrática y emancipadora de la Universidad, México, UNAM, Centro de Investigaciones Interdisciplinarias en Ciencias y Humanidades.

Suasnábar, C. (2004); Universidad e intelectuales: educación y política en la Argentina 1955-1976, Buenos Aires, Manantial.

Sutz, J. (1996) «Estudios sociales de la ciencia y la tecnología en América Latina: ¿en busca de una agenda?», en Albornoz (ed.) y otros, Ciencia y sociedad en América Latina, Universidad Nacional de Quilmes.

Teichler, U. (2006); "Reformas en educación superior desde una perspectiva comparada: respuestas diversas a desafíos similares", en Teichler, Ulrich Reformas de los modelos de la educación superior en Europa, Japón y América Latina: análisis comparados, Buenos Aires, Miño y Dávila editores.

UNESCO (1998) La educación superior en el siglo XXI: visión y acción, documento de trabajo de la Conferencia Mundial sobre la Educación Superior, París, 5 al 9 de octubre.

Varsavsky, O. (1994) Ciencia, política y cientificismo, Buenos Aires, Centro Editor de América Latina.

Varsavsky, Oscar (1968); "Sostiene Varsavsky", charla pronunciada en la Universidad Central de Venezuela en Junio de 1968. Versión electrónica en grupo de debate pol-cien. 
Vence Deza, Xavier (1995); Economía de la innovación y del cambio tecnológico. Una revisión crítica, Madrid, Siglo XXI de España editores.

Vessuri, H. (1998) «La pertinencia de la educación superior en un mundo en mutación», en Perspectivas, Vol. XXVIII, N 3, septiembre, pp. 417-433.

World Bank (2000), The Task Force on Higher Education and Society, Washington, Banco Mundial.

\footnotetext{
${ }^{1}$ El presente trabajo está basado en la tesis presentada en la Maestría de Ciencia Política y Sociología de la Facultad Latinoamericana en Ciencias Sociales (FLACSO).

${ }^{2}$ Licenciado en Economía (UBA). Magíster en Ciencia Política y Sociología (FLACSO). Integrante del grupo de investigación del Programa Educación, Economía y Trabajo (PEET) del Instituto de Investigaciones en Ciencias de la Educación, Facultad de Filosofía y Letras de la Universidad de Buenos Aires.
}

${ }^{3}$ Proyecto PICT Redes 00013 (ANPCyT/FONCyT). LAS UNIVERSIDADES FRENTE A LAS DEMANDAS SOCIALES Y PRODUCTIVAS. El rol promotor y la capacidad de intervención. Las respuestas de reorientación y cambio curricular. Sede Programa Educación, Economía y Trabajo - IICE- Facultad de Filosofía y Letras UBA. Directora y Responsable Administrativa Graciela C. Riquelme; Investigadora Responsable en UNMdP María Inés Pacenza; Investigadora Responsable en UNaM Emilce Cammarata.

${ }^{4}$ En realidad esta última denominación ya se utilizó en el PICTR00013 (2006), Documento de trabajo № 6 , Langer, Ariel.

${ }^{5}$ Consideramos importante desarrollar de forma autónoma la etapa histórica constituida a partir de la Reforma de 1918, no obstante, esto extendería en gran medida la tesis. Dejamos esta tarea para un trabajo posterior.

${ }^{6}$ Una de las formas en que esto puede observarse es en la confusión creciente en el significado de las funciones universitarias y en la fusión y mutación entre ellas. Ver Riquelme (2008b).

${ }^{7}$ La perspectiva analítica a la que responde este ejercicio es la diseñada en el Proyecto PICT Redes "Las Universidades frente a las demandas sociales y productivas. El rol promotor y la capacidad de intervención. Las respuestas de reorientación y cambio curricular" (PICTR00013).

${ }^{8}$ Una discusión detallada de este tipo de segmentación se encuentra en el anexo metodológico y en Riquelme y Langer (2008) y Riquelme (2008a).

${ }^{9}$ El total de la información necesaria sobre las entrevistas utilizadas en este capítulo y sobre el programa atlas- $t i$ utilizado en su procesamiento, puede consultarse en el Anexo Metodológico del Tomo I de los resultados del proyecto PICTR00013 (Riquelme, 2008).

${ }^{10}$ Como podrá observarse estos grupos temáticos no se encontrarán en el total de períodos históricos, sino que irán surgiendo según la importancia que hayan cobrado en cada momento. Como ya se mencionó este abordaje coincide con el diseño de las entrevistas del Proyecto PICT Redes "Las Universidades frente a las demandas sociales y productivas. El rol promotor y la capacidad de intervención. Las respuestas de reorientación y cambio curricular" (PICTR00013).

${ }^{11}$ Este rasgo también puede ser entendido en relación al modelo que evaluaremos en el sub-apartado siguiente (modelo tradicional argentino), donde la transferencia era concebida como formación de profesionales y técnicos y creación de conocimiento para que su aplicación sea realizada por instituciones distintas a la universidad (Frondizi, 1971).

Artigo recebido em: 08/10/10

Aprovado em: 25/10/10 